\title{
Diretrizes Baseadas em Evidências Diagnóstico e manejo da Síndrome de Guillain-Barré em dez etapas*
}

\author{
Evidence-Based Guidelines \\ Diagnosis and management of Guillain-Barré Syndrome in \\ ten steps
}

\section{Directrices Basadas en Evidencia \\ Diagnóstico y manejo del Síndrome de Guillain-Barré en diez etapas}

Sonja E. Leonhard ${ }^{1}$, Melissa R. Mandarakas ${ }^{1}$, Francisco A.A. Gondim², Kathleen Bateman ${ }^{3}$, Maria L.B. Ferreira ${ }^{4}$, David R. Cornblath ${ }^{5}$, Pieter A. van Doorn ${ }^{1}$, Mario E. Dourado ${ }^{6}$, Richard A.C. Hughes ${ }^{7}$, Badrul Islam ${ }^{8}$, Susumu Kusunoki ${ }^{9}$, Carlos A. Pardo ${ }^{5}$, Ricardo Reisin ${ }^{10}$, James J. Sejvar ${ }^{11}$, Nortina Shahrizaila ${ }^{12}$, Cristiane Soares ${ }^{13}$, Thirugnanam Umapathi ${ }^{14}$, Yuzhong Wang ${ }^{15}$, Eppie M. Yiu ${ }^{16,17,18,}$ Hugh J. Willison ${ }^{19}$, Bart C. Jacobs ${ }^{1,20}$

1.Departamento de Neurologia, Erasmus University Medical Center, Rotterdam, Netherlands. 2.Hospital Universitário Walter Cantidio, Universidade Federal do Ceará, Fortaleza-CE, Brasil. 3.Groote Schuur Hospital, University of Cape Town, Cape Town, South Africa.

4.Departamento de Neurologia, Hospital da Restauração, Recife-PE, Brasil.

5.Departamento de Neurologia, Johns Hopkins University School of Medicine, Baltimore-MD, USA.

6.Departamento de Medicina Integrativa, Hospital Universitário Onofre Lopes, Universidade Federal do Rio Grande do Norte, Natal, Brasil.

7.UCL Queen Square Institute of Neurology, University College London, London, UK.

8.International Centre for Diarrhoeal Disease Research, Bangladesh, Dhaka, Bangladesh.

9.Kindai University Faculty of Medicine, Osaka, Japan.

10. Hospital Británico, Buenos Aires, Argentina.

11.Centers for Disease Control and Prevention, Atlanta, GA, USA.

12.Departamento de Neurologia, University of Malaya, Kuala Lumpur, Malaysia.

13. Hospital Federal dos Servidores do Estado, Rio de Janeiro, Brasil.

14. National Neuroscience Institute, Singapore, Singapore.

15.Departamento de Neurologia, Affiliated Hospital of Jining Medical University, Jining, Shandong, China.

16.Departamento de Neurologia, The Royal Children's Hospital Melbourne, Melbourne, VIC, Australia.

17. Neurosciences Research, Murdoch Children's Research Institute, Melbourne, VIC, Australia. 18.Departamento de Pediatria, The University of Melbourne, Melbourne, VIC, Australia.

19. College of Medicine, Veterinary and Life Sciences, University of Glasgow, Glasgow,UK.

20.Departamento de Imunologia, Erasmus University Medical Center, Rotterdam, Netherlands.

\section{Resumo}

A síndrome de Guillain-Barré (SGB) é uma doença imunomediada rara, mas potencialmente fatal, dos nervos periféricos e das raízes nervosas, que é geralmente desencadeada por infecções. A incidência da SGB pode, portanto, aumentar durante surtos de doenças infecciosas, como foi observado durante a epidemia do vírus Zika em 2013 na Polinésia Francesa e em 2015 na América Latina. O diagnóstico e manejo da SGB podem ser complicados 
visto que sua apresentação clínica e o curso da doença são heterogêneos e não existem atualmente diretrizes clínicas internacionais disponíveis. Para auxiliar os médicos, especialmente em um cenário de surto, desenvolvemos uma diretriz globalmente aplicável para o diagnóstico e manejo da SGB. A diretriz se baseia no consenso de especialistas e na literatura atual e tem uma estrutura de dez etapas para facilitar seu uso na prática clínica. Primeiro fornecemos uma introdução aos critérios diagnósticos, às variantes clínicas e aos diagnósticos diferenciais da SGB. A seguir, as dez etapas abrangem o reconhecimento e o diagnóstico precoces da SGB, a internação na unidade de terapia intensiva, a indicação e seleção do tratamento, o monitoramento e tratamento da progressão da doença, o prognóstico do curso e resultado clínico e o manejo das complicações e sequelas.

Unitermos. Doenças autoimunes; Diagnóstico; Neuropatias periféricas; Doenças inflamatórias

\begin{abstract}
Guillain-Barré syndrome (GBS) is a rare, but potentially fatal, immune-mediated disease of the peripheral nerves and nerve roots that is usually triggered by infections. The incidence of GBS can therefore increase during outbreaks of infectious diseases, as was seen during the Zika virus epidemics in 2013 in French Polynesia and 2015 in Latin America. Diagnosis and management of GBS can be complicated as its clinical presentation and disease course are heterogeneous, and no international clinical guidelines are currently available. To support clinicians, especially in the context of an outbreak, we have developed a globally applicable guideline for the diagnosis and management of GBS. The guideline is based on current literature and expert consensus, and has a ten-step structure to facilitate its use in clinical practice. We first provide an introduction to the diagnostic criteria, clinical variants and differential diagnoses of GBS. The ten steps then cover early recognition and diagnosis of GBS, admission to the intensive care unit, treatment indication and selection, monitoring and treatment of disease progression, prediction of clinical course and outcome, and management of complications and sequelae.
\end{abstract}

Keywords. Autoimmune diseases; Diagnosis; Peripheral neuropathies; Inflammatory diseases

\title{
Resumen
}

El síndrome de Guillain-Barré (GBS) es una enfermedad inmunomediada de los nervios periféricos y raíces nerviosas poco frecuente, pero potencialmente mortal, que suele desencadenarse por infecciones. Por lo tanto, la incidencia de GBS puede aumentar durante los brotes de enfermedades infecciosas, como se observó durante la epidemia del virus Zika en 2013 en la Polinesia Francesa y en 2015 en América Latina. El diagnóstico y manejo del SGB puede ser complicado ya que su presentación clínica y el curso de la enfermedad son heterogéneos y actualmente no existen guías clínicas internacionales disponibles. Para ayudar a los médicos, especialmente en un escenario de brote, hemos desarrollado una guía aplicable a nivel mundial para el diagnóstico y manejo del SGB. La guía se basa en el consenso de expertos y en la literatura actual y tiene una estructura de diez pasos para facilitar su uso en la práctica clínica. Primero, proporcionamos una introducción a los criterios de diagnóstico, las variantes clínicas y los diagnósticos diferenciales del SGB. A continuación, los diez pasos incluyen el reconocimiento y el diagnóstico precoces del SGB, el ingreso a la unidad de cuidados intensivos, la indicación y selección del tratamiento, el seguimiento y el tratamiento de la progresión de la enfermedad, el pronóstico del curso y el resultado clínico y el manejo complicaciones y secuelas.

Palabras clave. Enfermedades autoinmunes; Diagnóstico; Neuropatías periféricas; Enfermedades inflamatorias

*Artigo publicado originalmente na Nat Rev Neurol 2019;15(11):671-683. doi: 10.1038/s41582-0190250-9 e autorizada reprodução na Revista Neurociências pela editora e pelos autores. Nota da editora: a Springer Nature permanece imparcial com relação a reivindicações jurisdicionais em mapas publicados e a afiliações institucionais. Informações revisadas por pares: a Nature Reviews Neurology agradece a Antonino Uncini e aos demais revisores anônimos por sua contribuição na revisão por pares deste trabalho.

Conflito de interesse: B.C.J. recebeu auxílio financeiro da Annexon Biosciences, da Baxter, da CSL Behring e da Grifols. D.R.C. recebeu honorários de consultoria da: Annexon Biosciences, argenx, Biotest Pharmaceuticals, Cigna Health Management, CSL Behring, DP Clinical, Grifols, Hansa Biopharma, New 
Enterprise Associates, Octapharma, Pharnext SAS, Polyneuron Pharmaceuticals, Seattle Genetics, Stealth BioTherapeutics, e Syntimmune. D.R.C também faz parte do conselho de monitoramento de segurança de dados da Pfizer, Sanofi, Alnylam Pharmaceuticals, PledPharma e Momenta Pharma. A Johns Hopkins University licenciou tecnologia para a AstraZeneca Pharmaceuticals, Genentech, Levicept, Seattle Genetics, Merrimack Pharmaceuticals, Levicept e Disarm Therapeutics, pela qual D.R.C. recebe royalties. P.A. v.D. recebeu um subsídio da Sanquin Blood Supply para o ensaio randomizado controlado SID-GBS e um subsídio da Grifols para realizar o estudo I-SID GBS. R.A.C.H. recebeu honorários de consultoria do Laboratoire Francais du Fractionnement et des Biotechnologies (LFB S.A.). S.K. recebeu honorários como palestrante da Teijin Pharma, Nihon Pharmaceutical e Japan Blood Products Organization, e apoio para pesquisa da Nihon Pharmaceutical e Japan Blood Products Organization. R.R. é apoiado por um subsídio da CSL Behring. N.S. recebe apoio para pesquisa da Hovid Berhad. Os demais autores declaram não ter conflito de interesses.

Endereço para correspondência: Bart C. Jacobs, e-mail: b.jacobs@erasmusmc.nl

\section{INTRODUÇÃO}

A síndrome de Guillain-Barré (SGB) é uma doença inflamatória do sistema nervoso periférico e é a causa mais comum de paralisia flácida aguda, com uma incidência global anual de aproximadamente 1 a 2 por 100.000 pessoas-ano ${ }^{1}$. A SGB ocorre com maior frequência em homens do que em mulheres e a incidência aumenta com a idade, embora todas as faixas etárias possam ser acometidas ${ }^{1}$. Os pacientes com SGB normalmente apresentam fraqueza e sinais sensitivos nas pernas que progridem para os braços e músculos cranianos, embora a apresentação clínica da doença seja heterogênea, existem diversas variantes clínicas diferentes. O diagnóstico da SGB se baseia no histórico do paciente e em exames neurológicos, eletrofisiológicos e do líquido cefalorraquidiano (LCR) ${ }^{2-4}$. Outras doenças que resultam em um quadro clínico semelhante ao da SGB devem ser descartadas ${ }^{4}$. Os estudos eletrofisiológicos fornecem evidências da disfunção do sistema nervoso periférico e podem diferenciar entre os subtipos da SGB: polirradiculoneuropatia desmielinizante inflamatória aguda 
(PDIA), neuropatia axonal motora aguda (NAMA) e neuropatia axonal motora e sensorial aguda (NAMSA) ${ }^{5}$. A progressão da doença pode ser rápida e a maioria dos pacientes atinge a incapacidade máxima dentro de 2 semanas. Cerca de $20 \%$ dos pacientes desenvolvem insuficiência respiratória e precisam de ventilação mecânica. É possível que ocorram arritmias cardíacas e instabilidade na pressão arterial devido ao comprometimento do sistema nervoso autônomo ${ }^{6}$. Este comprometimento do sistema nervoso autônomo contribui para a mortalidade, que é estimada em $3 \%$ a $10 \%$ dos pacientes, mesmo recebendo a melhor assistência médica disponível ${ }^{7-9}$. Após a fase inicial progressiva, os pacientes atingem uma fase de platô que pode durar de dias a semanas ou meses, após a qual eles começam a se recuperar, e $60 \%$ a $80 \%$ dos pacientes são capazes de caminhar sem auxílio seis meses após o surgimento da doença, com ou sem tratamento ${ }^{10,11}$. A SGB é uma doença monofásica, embora alguns pacientes possam apresentar deterioração após a estabilização ou melhora inicial mediante terapia, um fenômeno chamado flutuação relacionada ao tratamento (FRT). Podem ocorrer recidivas da SGB em $2 \%$ a $5 \%$ dos pacientes ${ }^{10,12-15}$.

Acredita-se que a SGB seja causada por uma resposta imunológica anormal às infecções, que resulta em dano aos nervos periféricos, apesar de a patogênese não ser totalmente compreendida. Em um subgrupo de pacientes com SGB, são encontrados anticorpos séricos antigangliosídeos, que existem em altas densidades no axolema 
e em outros componentes dos nervos periféricos ${ }^{16,17}$. A ativação do complemento, a infiltração de macrófagos e o edema são características típicas encontradas em nervos periféricos e raízes nervosas afetados de pacientes com $\mathrm{SGB}^{16}$.

A incidência da SGB pode aumentar durante surtos de doenças infecciosas que desencadeiam a doença ${ }^{18}$. Recentemente, as epidemias do vírus Zika na Polinésia Francesa em 2013 e na América Latina e Caribe em 20152016 foram vinculadas a um aumento no número de indivíduos diagnosticados com SGB ${ }^{19-21}$.

O surto do vírus Zika evidenciou a falta de diretrizes globalmente aplicáveis para o diagnóstico e manejo da SGB. Tais diretrizes são necessárias porque o diagnóstico da SGB pode ser desafiador devido à heterogeneidade da sua apresentação clínica, a um diagnóstico diferencial extenso e à falta de biomarcadores ou ferramentas diagnósticas de alta sensibilidade e especificidade. A diretriz para o tratamento e o cuidado de pacientes com SGB também é necessária porque a progressão da doença pode variar muito entre pacientes, o que dificulta uma abordagem totalmente prescritiva para o seu manejo. Além disso, as opções de tratamento são limitadas e caras, e muitos pacientes apresentam queixas e incapacidade residual, que podem ser difíceis de manejar.

A disponibilidade de diretrizes clínicas globalmente aplicáveis para a SGB é especialmente importante devido à probabilidade de novos surtos no futuro capazes de 
desencadear a SGB. Para criar esta diretriz clínica globalmente aplicável para a SGB, um grupo internacional de especialistas em SGB identificou as dez principais etapas no manejo da SGB, abrangendo diagnóstico, tratamento, monitoramento, prognóstico e manejo de longo prazo (Figura 1).

Para cada etapa, as recomendações foram fornecidas com base nas evidências encontradas na literatura e/ou na opinião de especialistas e se buscou obter consenso para cada recomendação de modo a concluir a diretriz. Estas recomendações têm o objetivo de auxiliar os profissionais de saúde na tomada de decisões clínicas. No entanto, o uso das informações contidas neste artigo é voluntário. Os autores não assumem a responsabilidade por qualquer lesão ou dano a pessoas ou propriedade que advenham ou estejam relacionados ao uso destas informações, ou por quaisquer erros ou omissões.

\section{MÉTODO}

Após o surto do vírus Zika e da sua associação a um aumento na incidência da SGB, foi lançada a Zika Preparedness Latin American Network (Rede de Enfrentamento ao Zika da América Latina) (ZikaPLAN) fundada pela União Europeia ${ }^{22}$. A nossa nova diretriz foi inicialmente preparada por participantes da rede ZikaPLAN, incluindo especialistas na SGB dos Países Baixos (S.E.L., M.R.M. e B.C.J.), do Brasil (F.G. e M.E.D.) e do Reino Unido (H.J.W.). 
1. Quando suspeitar de SGB

- Fraqueza bilateral rapidamente progressiva nos membros e/ou déficits sensoriais

- Hipo/arreflexia

- Paralisia facial ou bulbar

- Oftalmoplegia e ataxia
2. Como diagnosticar a SGB

- Verifique os critérios diagnósticos

- Exclua outras causas

- Leve em consideração:

- Exames laboratoriais de rotina

- Exame do LCR

- Estudos eletrofisiológicos

\section{Cuidados críticos}

\section{Quando internar na UT}

Um ou mais dos seguintes:

- Rápida progressão da fraqueza

- Disfunção grave autonômica ou de deglutição

- Evolução da angústia respiratória

- EGRIS >4

\section{Opções de tratamento}

- Imunoglobulina intravenosa $(0,4 \mathrm{~g} / \mathrm{kg}$ diariamente durante 5 dias)

- Plasmaférese (200 a 250 ml/kg por 5 sessões)

\section{Complicações precoces}

- Engasgo • Ulceração da

- Arritmias cardíacas córnea

- Infecções - Deficiência

- Trombose venosa nutricional profunda Hiponatremia

- Dor

- Delírios

- Depressão

- Retenção urinária

- Constipação
- Úlceras de pressão

- Neuropatia compressiva

- Contraturas dos membros

\section{Quando iniciar o tratamento}

Um ou mais dos seguintes:

- Incapacidade de caminhar por mais de 10 m sem auxílio

- Rápida progressão da fraqueza

- Disfunção grave autonômica ou de deglutição

- Insuficiência respiratória

\section{Monitoramento}

Avalie regularmente:

- Força muscular

- Função respiratória

- Função de deglutição

- Função autonômica

- Pressão arterial

- Frequência cardíaca/ritmo cardíaco

- Controle da bexiga/intestino

Frequência para as fases*

- Progressiva 2 a $4 \mathrm{~h}$

- Platô $6 \mathrm{~h}$

- Recuperação precoce $12 \mathrm{~h}$

\section{Progressão clínica}

Flutuação relacionada ao tratamento (FRT)

- Repita o mesmo tratamento:

Nenhuma resposta inicial ou recuperação incompleta:

- Nenhuma evidência para repetir o tratamento

\section{Cuidados de longo prazo}

\section{Previsão do resultado}

- Calcule a mEGOS na internação

- A recuperação pode continuar por mais de 3 anos após o surgimento

- A recorrência é rara (2 a 5\%)

\section{Reabilitação}

- Inicie o programa de reabilitação antecipadamente

- Faça o manejo das problemas de longo prazo: fadiga, dor, sofrimento psicológico

- Entre em contato com organizações de pacientes com SGB

Figura 1. Abordagem de dez etapas para o diagnóstico e manejo da síndrome de Guillain-Barré. Esse resumo em itens fornece uma visão geral de cada uma das dez etapas descritas na diretriz. A frequência do monitoramento depende do quadro clínico e deve ser avaliada em pacientes individuais. LCR, líquido cefalorraquidiano; EGRIS, Erasmus GBS Respiratory Insufficiency Score (Escore de Insuficiência Respiratória para SGB de Erasmus) (Quadro 3); SGB, síndrome de Guillain-Barré; UTI, unidade de terapia intensiva; UCI, unidade de cuidados intermediários; mEGOS, modified Erasmus GBS outcome score (Escala Erasmus de Prognóstico da SGB modificada) (Tabela suplementar 3); SMF, síndrome de Miller Fisher. 
Esses integrantes trouxeram para a diretriz a experiência clínica e de pesquisa específicas de suas funções de liderança em grandes projetos internacionais sobre a SGB (como o International GBS Outcome Study [Estudo Internacional do Prognóstico da SGB], IGOS), em conjunto com a experiência direta no manejo de grandes aumentos nos casos de SGB em regiões da América Latina afetadas pelo vírus Zika ${ }^{23}$. Para desenvolver as diretrizes preliminares, realizou-se uma série de reuniões presenciais entre os autores principais da comissão de redação (S.E.L., M.R.M., B.C.J. e H.J.W.), juntamente com reuniões individuais menores com colegas da América Latina (S.E.L., F.G. e M.E.D.) e correspondência contínua por e-mail para analisar os esboços e receber sugestões. Com base na opinião dos especialistas e por meio do consenso, este grupo identificou dez das etapas mais importantes no diagnóstico e manejo da SGB.

Em outubro de 2018, usando o PubMed e o Embase, integrantes da comissão de redação (S.E.L e M.R.M) realizaram pesquisas estruturadas na literatura para cada etapa, e os resultados dessas pesquisas forneceram a base para o primeiro esboço da diretriz. O principal critério de inclusão para as pesquisas na literatura foi: qualquer relato de caso, revisão, ensaio ou estudo publicado a partir de 2015 que tenha fornecido detalhes sobre 0 diagnóstico, tratamento, manejo ou prognóstico de pacientes com SGB. As publicações sobre a patogênese da SGB ou aquelas com foco em doenças não relacionadas à SGB, bem como 
publicações em idiomas que não o inglês ou o holandês, foram excluídas da revisão. As palavras-chave utilizadas na estratégia de pesquisa incluíram os seguintes termos do Cabeçalhos de Assuntos Médicos (MeSH): "Guillain-Barré syndrome" (síndrome de Guillain-Barré) E ["diagnosis" (diagnóstico) OU "therapeutics" (terapêutica) OU "treatment outcome" (resultado do tratamento) OU "prognosis" (prognóstico)]. Para obter literatura para tópicos mais específicos, termos adicionais do MeSH foram combinados com as palavras-chave da pesquisa inicial, incluindo "intravenous immunoglobulins" (imunoglobulinas intravenosas), "plasma exchange" (plasmaférese), "intensive care units" (unidades de terapia intensiva), "pregnancy" (gravidez), "Miller Fisher syndrome" (síndrome de Miller Fisher) e "HIV" (HIV). Após essa revisão da literatura mais recente, estudos de referência publicados antes de 2015 foram identificados pela comissão de redação (S.E.L., M.R.M., B.C.J. e H.J.W.) para inclusão, juntamente com outros artigos adicionais selecionados por meio da triagem das listas de referências das redações já incluídas e da consulta aos autores. Sempre que possível, as nossas recomendações com relação ao tratamento se basearam em revisões sistemáticas. Os autores buscaram a opinião de especialista para obter recomendações quando diante de uma maior limitação na disponibilidade de evidências (como no caso de estudos de coorte ou de caso-controle), por exemplo sobre tópicos relativos ao diagnóstico diferencial ou à reabilitação na SGB. 
Em consideração à variação global no âmbito da assistência à saúde e às variantes clínicas da $\mathrm{SGB}$, esse esboço inicial foi posteriormente revisado por um grupo internacional de especialistas em SGB da Argentina (R.R.), Austrália (E.M.Y.), Bangladesh (B.I.), Brasil (M.L.B.F. e C.S.), China (Y.W.), Colômbia (C.A.P.), Japão (S.K.), Malásia (N.S.), Países Baixos (P.A.D.), Singapura (T.U.), África do Sul (K.B.), EUA (D.R.C. e J.J.S.) e Reino Unido (R.A.C.H). No total, foram realizados sete ciclos de revisão para atingir um consenso. Para considerar a perspectiva de pacientes com SGB sobre o manejo da doença, a GBS/CIDP Foundation International (Fundação Internacional de SGB/PDIC), uma organização sem fins lucrativos que oferece suporte, educação, financiamento para pesquisas e defesa para pacientes com SGB ou polineuropatia desmielinizante inflamatória crônica (PDIC) e suas famílias, revisou o manuscrito e apresentou comentários durante o desenvolvimento da diretriz.

A fim de aumentar a utilização global dessas diretrizes, nós a traduzimos para o Português. Para garantir uma tradução fidedigna, nós agrupamos um grupo de co-autores para coordenar o processo de tradução e revisão das traduções. Esse grupo consistiu de um nativo da língua (F.A.A.G.), e D.R.C., R.A.H., H. J.W., B.C.J. e S.E.L.. A tradução foi realizada pela agência com certificação ISO Etymax. O manuscrito foi primeiramente traduzido para o Português e essa tradução foi então traduzida reversamente para o Inglês por um tradutor diferente. Ambas a tradução 
portuguesa e a tradução reversa inglesa foram revisadas por um comitê revisor e editada se considerada necessária.

\section{Etapa 1: quando suspeitar de SGB}

\section{Características clínicas típicas}

A SGB deve ser considerada como um diagnóstico em pacientes apresentando fraqueza bilateral rapidamente progressiva das pernas e/ou braços, na ausência de comprometimento do sistema nervoso central ou de outras causas óbvias. Os pacientes com a forma sensitivo-motora clássica da SGB apresentam parestesia ou perda sensitiva distal, acompanhada ou seguida por fraqueza que começa nas pernas e progride para os braços e músculos cranianos. Os reflexos estão reduzidos ou ausentes na maioria dos pacientes na apresentação e em quase todos os pacientes no nadir ${ }^{10,24}$. A disautonomia é comum e pode incluir a instabilidade da pressão arterial ou frequência cardíaca, disfunção pupilar e disfunção vesical ou intestinal ${ }^{25}$. Ocorre o relato frequente de dor que pode ser muscular, radicular ou neuropática ${ }^{26}$. O surgimento da doença é agudo ou subagudo e os pacientes geralmente atingem a incapacidade máxima dentro de 2 semanas $^{11}$. Diagnósticos alternativos devem ser considerados em pacientes que atingem a incapacidade máxima dentro de 24 horas ou após 4 semanas do surgimento da doença ${ }^{2,3}$. A SGB tem um curso clínico monofásico, embora FRTs e recidivas ocorram em uma minoria dos pacientes ${ }^{12,13}$. 


\section{Apresentação clínica atípica}

A SGB pode também se apresentar de uma forma atípica. A fraqueza e os sinais sensitivos, apesar de serem sempre bilaterais, podem ser assimétricos ou predominantemente proximais ou distais, e podem começar nas pernas, nos braços ou simultaneamente em todos os membros ${ }^{6,26}$. Além disso, a dor intensa e difusa ou a disfunção isolada do nervo craniano podem preceder 0 surgimento da fraqueza ${ }^{26}$. Em particular, crianças mais novas (<6 anos) podem apresentar características clínicas inespecíficas ou atípicas, como dor mal localizada, recusa em carregar peso, irritabilidade, meningismo ou marcha instável ${ }^{27,28}$. O não reconhecimento desses sinais como uma apresentação inicial da SGB pode levar ao atraso no diagnóstico ${ }^{28}$. Em uma minoria de pacientes com SGB atípica, particularmente naqueles apresentando apenas sinais motores (variante motora pura) e um subtipo de NAMA no exame eletrofisiológico, podem ser observados reflexos normais ou mesmo exagerados durante o curso da doença ${ }^{29}$.

\section{Variantes}

Alguns pacientes apresentam uma variante clínica persistente e distinta da SGB que não progride para o padrão clássico de perda sensitiva e fraqueza. Estas variantes incluem fraqueza sem sinais sensitivos (variante motora pura); fraqueza limitada aos nervos cranianos (paralisia facial bilateral com parestesia), aos membros superiores (fraqueza faringo-cérvico-braquial) ou aos membros 
inferiores (variante paraparética); e a síndrome de Miller Fisher (SMF), que em sua manifestação plena inclui oftalmoplegia, arreflexia e ataxia (Figura 2 e Tabela 1$)^{6,30,31 .}$

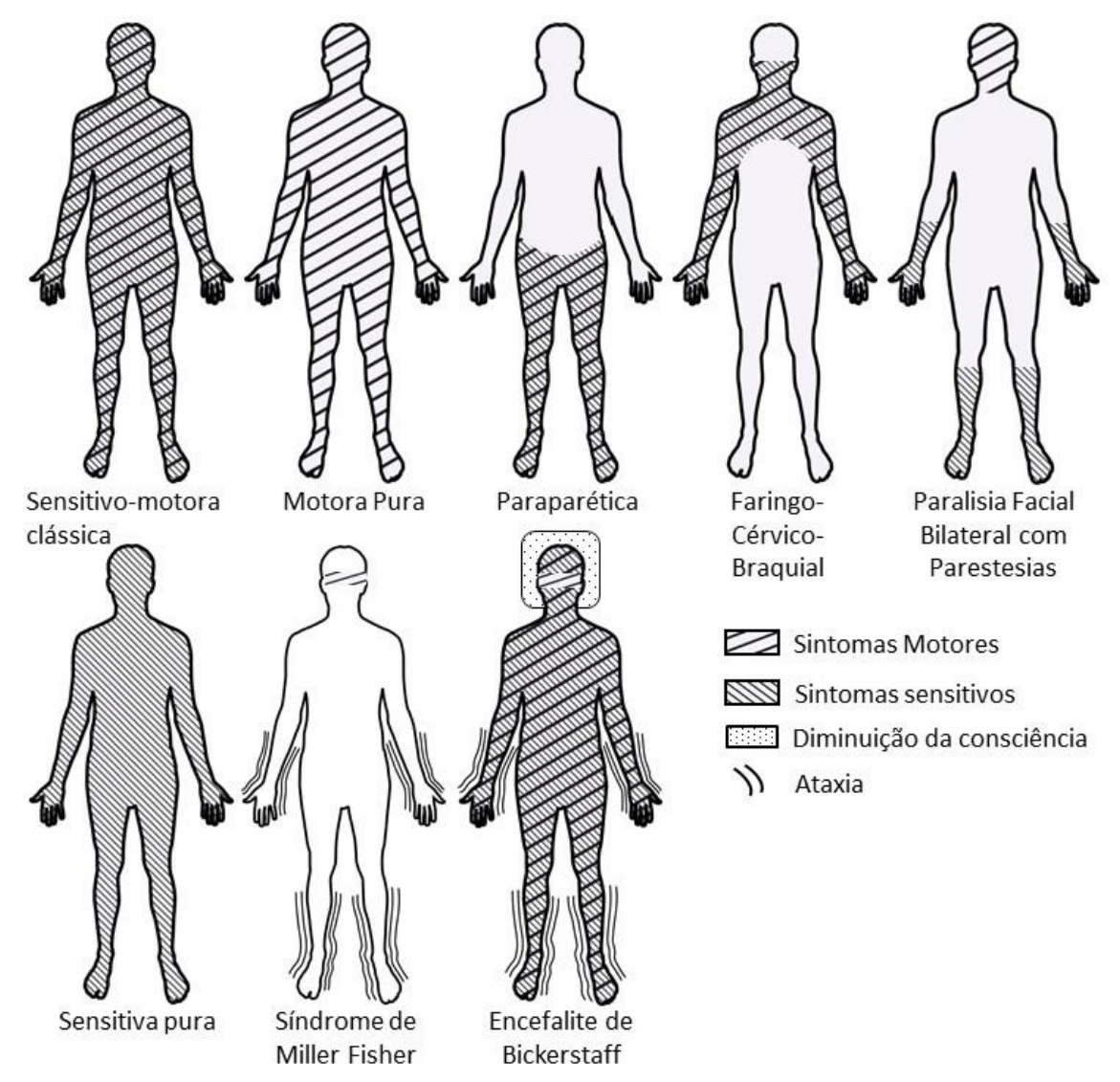

Figura 2. Padrão de sintomas nas variantes da síndrome de Guillain-Barré. Representação gráfica do padrão de sintomas tipicamente observado nas diferentes variantes clínicas da síndrome de Guillain-Barré (SGB). Os sintomas podem ser puramente motores, puramente sensitivos (raro) ou uma combinação de sintomas motores e sensitivos. Ataxia pode estar presente em pacientes com a síndrome de Miller Fisher, e tanto a consciência reduzida quanto a ataxia podem estar presentes em pacientes com encefalite do tronco encefálico de Bickerstaff. Os sintomas podem estar localizados em regiões específicas do corpo e o padrão de sintomas difere entre as variantes da SGB. Embora a paralisia facial bilateral com parestesias, a variante sensitiva pura e a encefalite do tronco encefálico de Bickerstaff estejam incluídas no espectro da SGB, elas não atendem aos critérios diagnósticos da SGB. Adaptado mediante permissão da referência ${ }^{113}$, BMJ Publishing Group Limited. 
Tabela 1. Variantes da síndrome de Guillain-Barré.

\begin{tabular}{|c|c|c|c|}
\hline Variante & $\begin{array}{l}\text { Frequência } \\
\text { (\% de casos } \\
\text { da SGB)a }\end{array}$ & Características clínicas & Referências \\
\hline $\begin{array}{l}\text { SGB sensitivo- } \\
\text { motora clássicab }\end{array}$ & 30 a 85 & $\begin{array}{l}\text { Sinais sensitivos e fraqueza simétricos e } \\
\text { rapidamente progressivos, com ausência ou } \\
\text { diminuição dos reflexos tendinosos, } \\
\text { normalmente atingindo o nadir dentro de } 2 \\
\text { semanas }\end{array}$ & $11,24,114,115$ \\
\hline Motora purac & 5 a 70 & Fraqueza motora sem sinais sensitivos & $5,11,24$ \\
\hline Paraparética & 5 a 10 & Paresia restrita às pernas & $10,24,115$ \\
\hline $\begin{array}{l}\text { Faringo-cérvico- } \\
\text { braquial }\end{array}$ & $<5$ & $\begin{array}{l}\text { Fraqueza nos músculos faríngeos, cervicais } \\
\text { e braquiais, sem fraqueza nos membros } \\
\text { inferiores }\end{array}$ & $10,114,115$ \\
\hline $\begin{array}{l}\text { Paralisia facial } \\
\text { bilateral com } \\
\text { parestesias }^{d}\end{array}$ & $<5$ & $\begin{array}{l}\text { Fraqueza facial bilateral, parestesia e } \\
\text { reflexos reduzidos }\end{array}$ & 114-116 \\
\hline Sensitiva purad & $<1$ & $\begin{array}{l}\text { Neuropatia sensitiva aguda ou subaguda, } \\
\text { sem outras deficiências }\end{array}$ & 117,118 \\
\hline $\begin{array}{l}\text { Síndrome de Miller } \\
\text { Fisher }\end{array}$ & 5 a 25 & $\begin{array}{l}\text { Oftalmoplegia, ataxia e arreflexia. Podem } \\
\text { ocorrer formas incompletas com ataxia } \\
\text { (neuropatia atáxica aguda) ou } \\
\text { oftalmoplegia (oftalmoplegia aguda) } \\
\text { isoladas. }{ }^{31} \text { Estima-se que apresente } \\
\text { sobreposição SGB sensitivo-motora clássica } \\
\text { em } 15 \% \text { dos pacientes }\end{array}$ & $11,24,114,116-119$ \\
\hline $\begin{array}{l}\text { Encefalite do } \\
\text { tronco encefálico } \\
\text { de Bickerstaff }^{d}\end{array}$ & $<5$ & $\begin{array}{l}\text { Oftalmoplegia, ataxia, arreflexia, sinais no } \\
\text { trato piramidal e comprometimento da } \\
\text { consciência, frequentemente se sobrepondo } \\
\text { à SGB sensitivo-motora }\end{array}$ & 114,115 \\
\hline
\end{tabular}

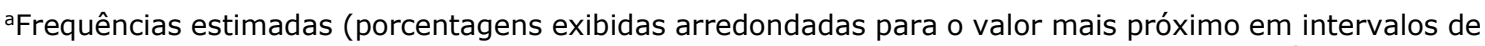
$5 \%$ ) com base em dez estudos de coorte (principalmente em adultos) em várias regiões geográficas ${ }^{10,11,24,114-119}$. As frequências mudam por região e estudo, contribuindo para a variabilidade. A maioria dos estudos apresenta viés devido à exclusão de algumas das variantes. 'bstima-se que a forma sensitivo-motora seja observada em $70 \%$ dos pacientes com SGB na Europa e nas Américas e em $30 \%$ a $40 \%$ dos casos na Ásia ${ }^{11}$. ${ }^{\mathrm{C}} \mathrm{A}$ variante motora pura é relatada em $5 \%$ a $15 \%$ dos pacientes com SGB na maioria dos estudos, mas é relatada em $70 \%$ dos casos em Bangladesh ${ }^{11,120}$. ${ }^{\text {d }}$ ão atende aos critérios diagnósticos normalmente usados da SGB, que exigem a presença de fraqueza bilateral nos membros ou o preenchimento dos critérios para a síndrome de Miller Fisher ${ }^{3,4}$. SGB, síndrome de Guillain-Barré.

Em geral, as variantes da SGB raramente são "puras" e frequentemente coincidem em parte com a síndrome clássica ou apresentam características que são típicas de outras formas variantes ${ }^{32}$. 
Além das variantes listadas acima, a ataxia sensitiva pura, a encefalite do tronco encefálico de Bickerstaff (BBE) e uma variante sensitiva pura também costumam ser incluídas no espectro da SGB, pois elas compartilham características clínicas ou fisiopatológicas com a SGB. No entanto, a inclusão dessas variantes clínicas está sujeita a discussões, pois não atendem os critérios diagnósticos da SGB (Quadro 1) 2,3,31. A variante sensitiva pura compartilha características clínicas com a forma sensitivo-motora clássica da SGB, exceto pela presença de sintomas e sinais motores ${ }^{31,33}$; a ataxia sensitiva pura e a SMF apresentam perfis clínicos que se sobrepõem; e pacientes com a BBE geralmente apresentam sintomas parecidos com os da SMF e, posteriormente, desenvolvem sinais de disfunção do tronco encefálico, incluindo comprometimento da consciência e sinais no trato piramidal ${ }^{30-32,34-36}$. Semelhante aos pacientes com a SMF, indivíduos com ataxia sensitiva ou BBE podem ter anticorpos IgG anti-GQ1b ou contra outros gangliosídeos no soro ${ }^{30,34}$. No entanto, se a SGB sensitiva pura, a ataxia sensitiva pura e a BBE são variantes da SGB e/ou uma forma incompleta da SMF está sujeito a discussões; e é necessário um trabalho diagnóstico cuidadoso quando se suspeita dessas variantes (Quadros 1 e 2) 31,33,35. 
Este quadro lista os critérios diagnósticos para a síndrome de Guillain-Barré (SGB) desenvolvidos pelo National Institute of Neurological Disorders and Stroke (NINDS) ${ }^{3}$ e posteriormente modificados em um artigo de revisão. ${ }^{6}$ Adicionamos algumas características que lançam dúvidas sobre o diagnóstico que não foram mencionadas nos critérios originais ${ }^{2,3,6}$ e fizemos algumas adaptações para melhorar a inteligibilidade. Estes critérios não são aplicáveis a algumas das variantes específicas da SGB, conforme descrito na Tabela 1.

Características necessárias para o diagnóstico

- Fraqueza bilateral progressiva dos braços e pernas (inicialmente, pode haver o envolvimento somente das pernas) ${ }^{a}$

- Reflexos tendinosos ausentes ou reduzidos nos membros afetados (em algum momento no curso clínico) $)^{a}$

Características que embasam fortemente o diagnóstico

- A fase progressiva dura de dias a quatro semanas (geralmente $<2$ semanas)

- Simetria relativa de sintomas e sinais

- Sintomas e sinais sensitivas relativamente leves (ausentes na variante motora pura) $)^{a}$

- Comprometimento do nervo craniano, principalmente paralisia facial bilaterala

- Disfunção autonômica

- Dor muscular ou radicular nas costas ou nos membros ${ }^{b}$

- $\quad$ Nível proteico elevado no líquido cefalorraquidiano (LCR); níveis proteicos normais não excluem o diagnóstico ${ }^{b}$

- Características eletrodiagnósticas da neuropatia sensitivo-motora ou motora (eletrofisiologia normal nos estágios iniciais não excluem o diagnóstico) ${ }^{\mathrm{b}}$

Características que lançam dúvidas sobre o diagnóstico

- Números elevados de células mononucleares ou polimorfonucleares no LCR $\left(>50 \times 10^{6} / \mathrm{I}\right)$

- Assimetria acentuada e persistente da fraqueza

- Disfunção vesical ou intestinal no surgimento ou persistente durante o curso da doençab

- Disfunção respiratória grave com fraqueza limitada nos membros no surgimento

- $\quad$ Sinais sensitivos com fraqueza limitada no surgimentoa

- Febre no surgimento

- Nadir $<24 \mathrm{~h}^{\mathrm{b}}$

- $\quad$ Nível sensitivo bem demarcado, indicando lesão na medula espinhala

- Hiperreflexia ou clônus ${ }^{b}$

- Resposta extensora do reflexo cutâneo plantarb

- Dor abdominalb

- Progressão lenta com fraqueza limitada e sem comprometimento respiratório

- Progressão continuada por >4 semanas após começarem os sintomas ${ }^{b}$

- $\quad$ Alteração de consciência (exceto na encefalite do tronco encefálico de Bickerstaff) ${ }^{\mathrm{b}}$ 
Quadro 2. Diagnóstico diferencial da síndrome de Guillain-Barré.

O diagnóstico diferencial da síndrome de Guillain-Barré é abrangente e altamente dependente das características clínicas do paciente individual. Aqui, apresentamos uma visão geral dos principais diagnósticos diferenciais, categorizados de acordo com sua localização no sistema nervoso.

\section{Sistema nervoso central}

- Inflamação ou infecção no tronco encefálico (por exemplo, sarcoidose, síndrome de Sjögren, neuromielite óptica ou distúrbio associado aos anticorpos anti-glicoproteína da mielina do oligodendrócito) ${ }^{a}$

- Inflamação ou infecção da medula espinhal (por exemplo, sarcoidose, síndrome de Sjögren ou mielite transversa aguda)

- Doenças malignas (por exemplo, metástases leptomeníngeas ou neurolinfomatose)

- Compressão do tronco encefálico ou da medula espinhal

- $\quad$ AVC do tronco encefálico

- Deficiência de vitaminas (por exemplo, encefalopatia de Wernickea, causada pela deficiência de vitamina B1, ou degeneração combinada subaguda da medula espinhal, causada pela deficiência de vitamina B12)

\section{Células do corno anterior}

- Mielite flácida aguda (por exemplo, como resultado de pólio, enterovírus D68 ou A71, vírus do Nilo ocidental, vírus da encefalite japonesa ou vírus da raiva)

\section{Raízes nervosas}

- Infecção (por exemplo, doença de Lyme, citomegalovírus, HIV, vírus Epstein-Barr ou vírus varicela zoster)

- Compressão

- Doença maligna leptomeníngea

Nervos periféricos

- Polirradiculoneuropatia desmielinizante inflamatória crônica (PDIC)

- Distúrbios metabólicos ou eletrolíticos (por exemplo, hipoglicemia, hipotireoidismo, porfiria ou deficiência de cobre)

- Deficiência de vitaminas (por exemplo, deficiência de vitamina B1 [também conhecida como beribéri], B12 ou $E$ )

- Toxinas (por exemplo, drogas, álcool, vitamina B6, chumbo, tálio, arsênio, organofosforado, etilenoglicol, dietilenoglicol, metanol ou n-hexano)

- Polineuropatia de doença grave

- Amiotrofia nevrálgica

- Vasculite

- Infecção (por exemplo, difteria ou HIV)

\section{Junção neuromuscular}

- Miastenia gravis

- Síndrome miastênica de Lambert-Eaton

- Neurotoxinas (por exemplo, botulismo, tétano, paralisia por carrapato ou envenenamento por picada de cobra)

- Intoxicação por organofosforado

\section{Músculos}

- Distúrbios metabólicos ou eletrolíticos (por exemplo, hipocalemia, paralisia periódica hipocalêmica tireotóxica, hipomagnesemia ou hipofosfatemia)

- Miosite inflamatória

- Rabdomiólise aguda

- Miopatia tóxica induzida por drogas (por exemplo, induzida por colchicina, cloroquina, emetina ou estatinas)

- Doença mitocondrial

\section{Outros}

- Transtorno conversivo ou funcional

aDiagnóstico diferencial para encefalite do tronco encefálico de Bickerstaff. 


\section{Eventos anteriores}

Cerca de dois terços dos pacientes que desenvolvem a SGB relatam sintomas de uma infecção nas seis semanas anteriores ao surgimento da doença ${ }^{11}$. Acredita-se que essas infecções desencadeiam a resposta imunológica que causa a $\mathrm{SGB}^{6}$. Em estudos de caso-controle, seis patógenos foram temporalmente associados à SGB: Campylobacter jejuni, citomegalovírus, vírus da hepatite $\mathrm{E}$, Mycoplasma pneumoniae, vírus Epstein-Barr e vírus Zika18,20,37. Foi sugerida uma ligação entre outros patógenos e a SGB com base nas evidências de séries de casos ou de estudos epidemiológicos, mas seu papel na patogênese da SGB é incerto ${ }^{38-43}$. Em geral, a ausência de uma enfermidade anterior não exclui um diagnóstico de SGB, já que as infecções putativas ou outros estímulos imunológicos podem ser subclínicos.

Vacinas foram vinculadas à SGB pela primeira vez em 1976, quando se observou um aumento de 7,3 vezes no risco de SGB em indivíduos não militares nos EUA, que haviam recebido a vacina contra a gripe "suína"44. A relação epidemiológica entre outras vacinas e a SGB foi examinada muitas vezes desde então, mas somente dois estudos posteriores mostraram uma relação entre a SGB e vacinas contra a gripe ${ }^{45,46}$. Esses estudos sugeriram um aumento de aproximadamente um caso adicional de SGB por um milhão de vacinações, o que é muitas ordens de grandeza inferior ao observado para a vacina contra a gripe de $1976^{47,48}$. 
Nenhuma outra vacina foi vinculada de maneira convincente à $\mathrm{SGB}^{15}$.

Com base nas informações da série de casos e na plausibilidade biológica, foi relatada uma relação entre a administração de imunobiológicos (por exemplo, antagonistas do fator de necrose tumoral, inibidores de checkpoint imunológico ou interferons tipo I) e a $\mathrm{SGB}^{49}$. Outros eventos, incluindo, dentre outros, cirurgia e doenças malignas, foram temporalmente relacionados à SGB, mas essas relações não possuem uma justificativa biológica clara e as evidências epidemiológicas são limitadas ${ }^{50,51}$.

\section{Etapa 2: como diagnosticar a SGB}

$\mathrm{Na}$ ausência de biomarcadores suficientemente sensíveis e específicos para a doença, o diagnóstico da SGB se baseia no histórico e exame físico, e é corroborado pelas investigações complementares, como o exame do LCR e os estudos eletrodiagnósticos. Os dois conjuntos de critérios diagnósticos mais comumente usados da SGB foram criados pelo National Institute of Neurological Disorders and Stroke (Instituto Nacional de Transtornos Neurológicos e Acidente Vascular Cerebral) (NINDS) em 1978 (revisado em 1990) (Quadro 1) ${ }^{2,3}$ e pela Brighton Collaboration (Colaboração Brighton) em 2011 (Tabela suplementar 1; disponível em: https://www.ncbi.nlm.nih.gov/pmc/articles/PMC6821638/bi n/41582 2019250 MOESM1 ESM.pdf) $)^{2-4}$. Ambos os conjuntos de critérios foram projetados para investigar a associação epidemiológica entre a SGB e as vacinações, mas 
têm sido usados desde então em outros ensaios e estudos clínicos. Consideramos os critérios do NINDS mais adequados para o médico, pois apresentam as características clínicas das formas típicas e atípicas da SGB, embora os critérios da Brighton Collaboration também sejam importantes, amplamente utilizados e possam auxiliar 0 médico a classificar casos da SGB típica ou SMF de acordo com a certeza diagnóstica. Diversos diagnósticos diferenciais também devem ser considerados diante da suspeita de SGB e alguns sintomas devem levantar a suspeita de diagnósticos alternativos (Quadros 1 e 2 ). O papel das investigações complementares na confirmação de um diagnóstico de SGB é descrita com mais detalhes na próxima seção.

\section{Investigações laboratoriais}

Os exames laboratoriais são orientados pelo diagnóstico diferencial em pacientes individuais; mas, em geral, todos os pacientes com suspeita de SGB farão hemogramas completos e exames de sangue para glicose, eletrólitos, função renal e enzimas hepáticas. Os resultados desses exames podem ser usados para excluir outras causas de paralisia flácida aguda, como infecções ou disfunções metabólicas ou eletrolíticas (Quadro 2). É possível realizar outros exames específicos com o objetivo de excluir outras doenças capazes de imitar a SGB (Quadro 2). Exames realizados para infecções anteriores geralmente não contribuem para o diagnóstico da SGB, mas podem fornecer informações epidemiológicas importantes durante surtos de 
doenças infecciosas, como observado em surtos passados de infecção pelo vírus Zika e pelo C. jejuni19,52. O valor diagnóstico de medir os níveis séricos de anticorpos antigangliosídeos é limitado e depende do ensaio. Um resultado de teste positivo pode ser útil, especialmente quando existe dúvida no diagnóstico, mas um resultado de teste negativo não exclui SGB ${ }^{53}$. Os anticorpos anti-GQ1b são encontrados em até $90 \%$ dos pacientes com SMF ${ }^{17,54}$ e, portanto, possuem maior valor diagnóstico em pacientes com suspeita de SMF do que em pacientes com SGB clássica ou outras variantes. Em caso de suspeita da SGB, recomendamos que não se espere pelo resultado do exame de anticorpos antes de iniciar o tratamento.

\section{Exame do líquido cefalorraquidiano}

O exame do LCR é usado principalmente para excluir outras causas de fraqueza que não a SGB e deve ser realizado durante a avaliação inicial do paciente. O achado clássico na SGB é a combinação de um nível proteico elevado no LCR e uma contagem celular normal no LCR (conhecida como dissociação albumino-citológica) ${ }^{55}$. No entanto, os níveis proteicos são normais em $30 \%$ a $50 \%$ dos pacientes na primeira semana após o surgimento da doença e em $10 \%$ a $30 \%$ dos pacientes na segunda semana10,11,24,56. Sendo assim, os níveis proteicos normais no LCR não excluem um diagnóstico de SGB. Uma pleocitose acentuada (>50 células $\mu^{-1}$ ) sugere outras patologias, como uma doença maligna leptomeníngea ou doenças infecciosas ou inflamatórias da 
medula espinhal ou raízes nervosas. Uma pleocitose leve (10 a 50 células $\mu^{-1}$ ), embora compatível com SGB, deve ainda assim incitar os médicos a considerar diagnósticos alternativos, como as causas infecciosas de polirradiculite (Quadro 2) ${ }^{10,11 .}$

\section{Estudos eletrodiagnósticos}

Os estudos eletrodiagnósticos não são obrigatórios no diagnóstico da SGB. No entanto, recomendamos a realização desses estudos sempre que possível, pois eles são úteis para auxiliar o diagnóstico, particularmente em pacientes com um quadro atípico. Em geral, os exames eletrofisiológicos em pacientes com SGB revelarão uma polineuropatia ou polirradiculoneuropatia sensitivo-motora, sinalizada por velocidades de condução reduzidas, amplitudes reduzidas do potencial evocado somatossensitivo e motor, dispersão temporal anormal e/ou bloqueios parciais da condução motora 6 ,57. O típico para a SGB é um "padrão de preservação sural", no qual o potencial de ação do nervo sural sensitivo está normal enquanto os potenciais de ação dos nervos ulnar e mediano sensitivos estão anormais ou até ausentes ${ }^{6,57}$. No entanto, as medidas eletrofisiológicas podem estar normais quando realizadas no início do curso da doença (até uma semana após o surgimento dos sintomas) ou em pacientes com fraqueza inicial proximal, doença leve, progressão lenta ou em variantes clínicas ${ }^{5,58,59}$. Nesses pacientes, pode ser útil repetir o estudo eletrodiagnóstico depois de 2 a 3 semanas. Em pacientes com SMF, os resultados dos estudos 
eletrodiagnósticos são geralmente normais ou evidenciam apenas uma redução na amplitude dos potenciais de ação dos nervos sensitivos ${ }^{4,60}$.

Os estudos eletrodiagnósticos também podem diferenciar os três subtipos eletrofisiológicos da SGB clássica: PDIA, NAMA e NAMSA. Existem vários conjuntos de critérios eletrodiagnósticos que visam classificar os pacientes nesses diferentes subtipos eletrofisiológicos com base na presença de características eletrodiagnósticas específicas em pelo menos dois nervos motores. Ainda não se chegou a um consenso internacional sobre qual conjunto de critérios define melhor os subtipos eletrofisiológicos ${ }^{5,52,61}$. Contudo, cerca de um terço dos pacientes com SGB não atendem a nenhum desses critérios e são classificados como "duvidosos" ou "inexcitáveis". Estudos têm demonstrado que a repetição dos estudos eletrodiagnósticos 3 a 8 semanas após o surgimento da doença pode auxiliar na classificação eletrodiagnóstica, permitindo a classificação de casos que inicialmente eram não classificáveis ou a reclassificação de casos que inicialmente foram classificados como PDIA, NAMA ou NAMSA, embora essa prática seja controversa ${ }^{62-64}$.

\section{Imaginologia}

A RM não faz parte da avaliação diagnóstica de rotina da SGB, mas pode ser útil, particularmente para excluir diagnósticos diferenciais, como infecção no tronco encefálico, acidente vascular cerebral, inflamação da medula espinhal ou das células do corno anterior, compressão de raiz 
nervosa ou doença maligna leptomeníngea (Quadro 2). A presença de realce de raiz nervosa na RM com gadolínio é uma característica inespecífica, mas sensível, da $\mathrm{SGB}^{65}$ e pode corroborar um diagnóstico de SGB, especialmente em crianças pequenas, nas quais a avaliação clínica e eletrofisiológica pode ser desafiadora66. Tendo em vista os surtos recentes de mielite flácida aguda em crianças pequenas, cuja apresentação clínica pode imitar a SGB, o potencial uso da RM para diferenciar entre esses dois diagnósticos deve receber atenção especial ${ }^{67,68}$. No entanto, os médicos devem estar cientes de que o realce de raiz nervosa pode ser encontrado em uma minoria dos sujeitos com mielite flácida aguda ${ }^{69}$.

Uma possível nova ferramenta diagnóstica para a SGB é o exame de imagem dos nervos periféricos por ultrassom, que revelou raízes nervosas cervicais aumentadas no início do curso da doença, indicando a importância da inflamação da raiz espinhal como um mecanismo patológico precoce ${ }^{70,71}$. Essa técnica pode, portanto, ajudar a estabelecer o diagnóstico de SGB no início do curso da doença, embora sejam necessárias validações adicionais.

\section{Etapa 3: quando internar na UTI}

Os motivos para internar os pacientes na unidade de terapia intensiva (UTI) incluem os seguintes: evolução da angústia respiratória com insuficiência respiratória iminente, disfunção autonômica cardiovascular grave (por exemplo, arritmias ou variação acentuada da pressão arterial), 
disfunção grave da deglutição ou diminuição do reflexo da tosse e rápida progressão da fraqueza ${ }^{72,73}$. Um estado de insuficiência respiratória iminente é definido como sinais clínicos de angústia respiratória, incluindo falta de ar em repouso ou enquanto fala, a incapacidade de contar até 15 em uma única respiração, o uso dos músculos acessórios da respiração, frequência cardíaca ou respiratória aumentada, capacidade vital $<15$ a $20 \mathrm{ml} / \mathrm{kg}$ ou $<1 \mathrm{l}$, ou medições anormais de gasometria arterial ou oximetria de pulso.

Como até $22 \%$ dos pacientes com SGB precisam de ventilação mecânica na primeira semana da internação, os pacientes com risco de insuficiência respiratória devem ser identificados 0 mais cedo possível ${ }^{74}$. A ferramenta prognóstica Erasmus GBS Respiratory Insufficiency Score (Escore de Insuficiência Respiratória para SGB de Erasmus) (EGRIS) foi desenvolvida para essa finalidade e calcula a probabilidade $(1 \%$ a $90 \%$ ) de um paciente precisar de ventilação dentro de uma semana após a avaliação (Quadro $3)^{74}$.

Os fatores de risco para ventilação mecânica prolongada incluem a incapacidade de erguer os braços do leito uma semana após a intubação e um subtipo axonal ou nervos não excitáveis nos estudos eletrofisiológicos ${ }^{75}$. Devese considerar a traqueostomia precoce em pacientes que apresentarem esses fatores de risco. 
Quadro 3: Erasmus GBS Respiratory Insufficiency Score.

O escore de insuficiência respiratória para a síndrome de Guillain-Barré (SGB) de Erasmus (EGRIS) calcula a probabilidade de um paciente com SGB precisar de ventilação mecânica dentro de uma semana após a avaliação e se baseia em três medidas principais. Cada medida é categorizada e recebe uma pontuação específica; a soma dessas pontuações resulta em um EGRIS geral para o paciente (entre 0 e 7). Um EGRIS de 0 a 2 indica um risco baixo de intervenção mecânica (4\%), de 3 a 4 indica um risco intermediário (24\%) e $\geq 5$ indica um risco alto (65\%). Esse modelo se baseia em uma população de pacientes holandeses com SGB (idade $>6$ anos) e ainda não foi internacionalmente validado. Portanto, pode não ser válido em outras faixas etárias ou populações. O consórcio International GBS Outcome Study (IGOS) disponibilizou um recurso on-line que calcula automaticamente o EGRIS para um paciente com base nas respostas a uma série de perguntas (consulte "Links relacionados"). A soma de escores do Medical Research Council (MRC) é a soma dos escores na escala do MRC para: fraqueza muscular na abdução bilateral dos ombros, flexão do cotovelo, extensão do punho, flexão do quadril, extensão do joelho e dorsiflexão do tornozelo. O escore do MRC varia entre 0 e 60, com 60 indicando a ausência de fraqueza e 0 a paralisia completa.

\begin{tabular}{|l|c|c|}
\hline Medida & Categorias & Escore \\
\hline $\begin{array}{l}\text { Dias entre o surgimento da fraqueza e a } \\
\text { internação hospitalar }\end{array}$ & $>7$ dias & 0 \\
& 4 a 7 dias & 1 \\
& $\leq 3$ dias & 2 \\
\hline $\begin{array}{l}\text { Fraqueza bulbar e/ou facial na internação } \\
\text { hospitalar }\end{array}$ & Ausente & 0 \\
& Presente & 1 \\
\hline $\begin{array}{l}\text { Soma de escores do MRC na internação } \\
\text { hospitalar }\end{array}$ & 60 a 51 & 0 \\
& 50 a 41 & 1 \\
& 40 a 31 & 2 \\
& 30 a 21 & 3 \\
& $\leq 20$ & 4 \\
\hline EGRIS NA & 0 a 7 \\
\hline \multicolumn{2}{|c|}{ NA = não aplicável. Adaptado da TABELA 2 da referência ${ }^{61}}$.
\end{tabular}

\section{Etapa 4: quando iniciar o tratamento}

A terapia imunomoduladora deve ser iniciada se os pacientes forem incapazes de caminhar $10 \mathrm{~m}$ sem auxílio ${ }^{76,77}$. As evidências da eficácia do tratamento em pacientes que ainda conseguem andar sem auxílio são limitadas, mas o tratamento deve ser considerado principalmente se esses pacientes exibirem fraqueza 
rapidamente progressiva ou outros sintomas graves, como disfunção autonômica, insuficiência bulbar ou insuficiência respiratória78-80. Ensaios clínicos já demonstraram um efeito terapêutico para a imunoglobulina intravenosa (IVIg) quando iniciada dentro de duas semanas do início da fraqueza e para a plasmaférese quando iniciada dentro de quatro semanas ${ }^{76,77}$. Além desses períodos de tempo, faltam evidências sobre a eficácia.

\section{Etapa 5: opções de tratamento}

\section{Estratégias de tratamento}

IVIg $(0,4 \mathrm{~g}$ por $\mathrm{kg}$ de peso corporal, diariamente, por 5 dias) e plasmaférese (200 a $250 \mathrm{ml}$ de plasma por kg de peso corporal em cinco sessões) são tratamentos igualmente eficazes para a SGB ${ }^{76,80}$. A IVIg e a plasmaférese possuem riscos comparáveis de eventos adversos, embora estudos iniciais tenham demonstrado ser mais provável que a plasmaférese seja descontinuada em comparação à IVIg ${ }^{76,81}$. Como a IVIg também é mais fácil de administrar e, geralmente, mais amplamente disponível do que a plasmaférese, normalmente ela é o tratamento de escolha. Além da IVIg e da plasmaférese, não se comprovou a eficácia de nenhum outro procedimento ou medicamento no tratamento da SGB. Apesar de se esperar que os corticosteroides fossem benéficos na redução da inflamação e, portanto, da progressão da doença na SGB, oito ensaios clínicos controlados e randomizados sobre a eficácia dos corticosteroides na SGB mostraram não haver benefícios 
significativos, e o tratamento com corticosteroides orais demonstrou inclusive possuir um efeito negativo no resultado ${ }^{82}$. Além disso, a plasmaférese seguida pela IVIg não é mais eficaz do que qualquer um dos tratamentos isolados e não há evidências suficientes disponíveis sobre a eficácia de um tratamento adjuvante com metilprednisolona intravenosa em pacientes tratados com IVIg82,83. Em unidades clínicas com recursos limitados, a plasmaférese de pequeno volume pode ser uma alternativa econômica e relativamente segura à plasmaférese convencional, mas essa abordagem não pode ser recomendada para uso geral até que sua eficácia tenha sido comprovada em ensaios adicionais $^{84}$.

O tratamento antimicrobiano ou antiviral pode ser considerado em pacientes com SGB apresentando uma infecção em andamento. No entanto, as infecções anteriores geralmente já se resolveram antes do surgimento da fraqueza.

\section{Grupos específicos de pacientes}

Variantes da SGB

Pacientes com a SMF pura tendem a ter um curso relativamente leve da doença e a maioria se recupera completamente, sem tratamento, em até seis meses ${ }^{85}$. Sendo assim, normalmente não se recomenda o tratamento nesse grupo de pacientes, mas eles devem ser monitorados com atenção, pois um subgrupo pode desenvolver fraqueza nos membros, paralisia facial ou bulbar ou insuficiência 
respiratória32,80. A gravidade do curso da doença da BBE justifica o tratamento com IVIg ou plasmaférese, embora as evidências para a eficácia do tratamento neste contexto sejam limitadas ${ }^{34,85}$. Não há atualmente evidências disponíveis com relação ao tratamento de outras variantes clínicas, apesar de muitos especialistas administrarem IVIg ou plasmaférese ${ }^{86}$.

\section{Gestantes}

Não há contraindicações para a IVIg ou para a plasmaférese durante a gravidez. Contudo, é possível que a IVIg seja preferida, já que a plasmaférese requer considerações e monitoramentos adicionais ${ }^{87-89}$.

\section{Crianças}

Não há indícios de que seja necessário desviar-se da prática padrão para adultos ao tratar crianças com $\mathrm{SGB}^{76,78,90}$. As evidências sobre as eficácias relativas da plasmaférese e da IVIg em crianças são limitadas ${ }^{90}$. No entanto, como a plasmaférese só está disponível em centros com experiência no seu uso e parece produzir mais desconforto e maiores taxas de complicações em crianças do que a IVIg, a IVIg geralmente é a terapia de primeira linha para crianças com SGB ${ }^{91}$. Embora alguns centros pediátricos administrem a IVIg a $2 \mathrm{~g}$ por kg (peso corporal) por 2 dias, ao invés do regime de adulto padrão de $2 \mathrm{~g}$ por $\mathrm{kg}$ (peso corporal) por 5 dias, um estudo indicou que as FRTs foram 
mais frequentes no regime de 2 dias ( 5 de 23 crianças) do que no regime de 5 dias ( 0 de 23 crianças) ${ }^{78}$.

\section{Etapa 6: monitoramento da progressão da doença}

É necessária uma avaliação periódica para monitorar a progressão da doença e a ocorrência de complicações. Em primeiro lugar, recomenda-se a medição rotineira da função respiratória, já que nem todos os pacientes com insuficiência respiratória apresentarão sinais clínicos de dispneia. Essas medições respiratórias podem incluir o uso dos músculos acessórios da respiração, contar durante a expiração de uma respiração após inspiração para a capacidade total (uma única contagem respiratória $\leq 19$ é preditora da necessidade de ventilação mecânica), capacidade vital e pressão inspiratória e expiratória máxima ${ }^{73,92}$. Os médicos devem considerar a "regra 20/30/40", pela qual o paciente é considerado em risco de insuficiência respiratória se a capacidade vital for $<20 \mathrm{ml} / \mathrm{kg}$, a pressão inspiratória

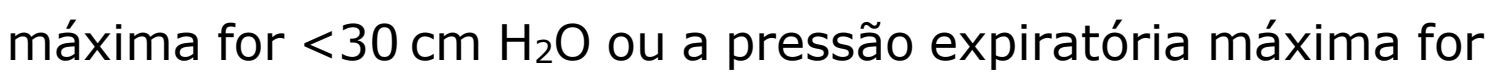
$<40 \mathrm{~cm} \mathrm{H} \mathrm{H}_{2} \mathrm{O}^{93}$. Em segundo lugar, a força muscular no pescoço, braços e pernas deve ser avaliada usando a escala de classificação do Medical Research Council (Conselho de Pesquisa Médica) ou uma escala semelhante, e a incapacidade funcional deve ser avaliada na escala de incapacidade da SGB (Tabela suplementar 2; disponível em: https://www.ncbi.nlm.nih.gov/pmc/articles/PMC6821638/bi n/41582 2019250 MOESM1 ESM.pdf), uma ferramenta amplamente utilizada para documentar o curso da doença da 
$\mathrm{SGB}^{94}$. Em terceiro lugar, os pacientes devem ser monitorados quanto a dificuldades para deglutir e tossir. Por último, deve-se avaliar a disfunção autonômica usando um eletrocardiograma e o monitoramento da frequência cardíaca, pressão arterial e função vesical e intestinal.

A natureza e a frequência do monitoramento dependem da taxa de deterioração, da presença ou ausência de disfunção autonômica, da fase da doença e das condições da unidade de assistência à saúde, e devem ser cuidadosamente avaliadas em cada paciente individual. Até dois terços das mortes de pacientes com SGB ocorrem durante a fase de recuperação e são, na maioria, causadas por disfunção cardiovascular e respiratória6,7,11. Portanto, recomendamos que os médicos permaneçam alertas durante essa fase e monitorem o paciente para detectar possíveis arritmias, mudanças na pressão arterial ou angústia respiratória causada por tampões de muco. Esse monitoramento é especialmente importante em pacientes que tiveram alta da UTI recentemente e naqueles com fatores de risco cardiovascular.

\section{Etapa 7: manejo de complicações precoces}

As complicações da SGB podem causar morbidade grave e morte ${ }^{95}$. Algumas destas complicações, incluindo úlceras de pressão, infecções nosocomiais (por exemplo, pneumonia ou infecções do trato urinário) e trombose venosa profunda, podem ocorrer em qualquer paciente hospitalizado e acamado, e recomendam-se as medidas 
preventivas e o tratamento padrão. Outras complicações são mais específicas para a SGB, tais como: a incapacidade de deglutir com segurança em pacientes com paralisia bulbar; a ulceração da córnea em pacientes com paralisia facial; e as contraturas, ossificação e paralisias por pressão em membros de pacientes com fraqueza nos membros (Tabela 2). A dor, as alucinações, a ansiedade e a depressão também são frequentes na SGB e os cuidadores devem perguntar especificamente aos pacientes se eles estão tendo esses sintomas, principalmente se os pacientes tiverem capacidade limitada de comunicação e/ou estiverem na UTI. A identificação e o tratamento adequado dos sintomas psicológicos e da dor em um estágio inicial são importantes porque esses sintomas podem ter um grande impacto no bem-estar dos pacientes. Os cuidadores devem também estar cientes de que pacientes com SGB, mesmo aqueles com paralisia total, normalmente têm a consciência, a visão e a audição intactas. É importante, portanto, estar atento ao que é dito na beira do leito e explicar a natureza dos procedimentos aos pacientes para reduzir a ansiedade. 0 manejo adequado das complicações é melhor realizado por uma equipe multidisciplinar, o que pode incluir enfermeiros, fisioterapeutas, especialistas em reabilitação, terapeutas ocupacionais, fonoaudiólogos e nutricionistas. 
Tabela 2. Complicações importantes da síndrome de Guillain-Barré.

\begin{tabular}{ll}
\hline Complicação & Quando ficar alerta \\
\hline Engasgo & Paralisia bulbar \\
\hline Arritmias cardíacas & Todos os pacientes \\
\hline Infecções nosocomiais (por exemplo, pneumonia, & Paralisia facial e bulbar, imobilidade, disfunção \\
sepse ou infecção do trato urinário) & vesical, ventilação mecânica \\
\hline Dor e alodinia tátil & Comunicação limitada \\
\hline Delírios & Comunicação limitada \\
\hline Depressão & Comunicação limitada \\
\hline Retenção urinária & Todos os pacientes \\
\hline Constipação & Imobilidade \\
\hline Ulceração da córnea & Paralisia facial \\
\hline Deficiência nutricional & Paralisia facial e bulbar \\
\hline Hiponatremia & Todos os pacientes \\
\hline Úlceras de pressão & Imobilidade \\
\hline Neuropatia compressiva & Imobilidade \\
\hline Ossificações e contraturas dos membros & Fraqueza intensa por um período de tempo \\
\hline
\end{tabular}

Complicações importantes da síndrome de Guillain-Barré (SGB) ${ }^{72}$. A maioria dessas complicações pode ocorrer em qualquer paciente com SGB, a qualquer momento, mas a segunda coluna mostra quando é mais provável que ocorram e/ou quando se deve ficar especialmente alerta.

\section{Etapa 8: manejo da progressão clínica}

\section{Resposta insuficiente ao tratamento}

Cerca de $40 \%$ dos pacientes tratados com doses padrão de plasmaférese ou IVIg não melhoram nas primeiras 4 semanas seguintes ao tratamento ${ }^{80,82}$. Tal progressão da doença não implica que o tratamento seja ineficaz, já que a progressão poderia ter sido pior sem a terapia 6 . Os médicos podem considerar repetir o tratamento ou mudar para um tratamento alternativo, mas no momento não existem evidências de que essa abordagem melhorará o 
resultado96,97. Há um ensaio clínico em andamento investigando o efeito da administração de uma segunda dose de IVIg $^{98}$.

\section{Flutuações relacionadas ao tratamento}

As FRTs são observadas em 6\% a 10\% dos pacientes com SGB e são definidas como a progressão da doença que ocorre dentro de dois meses após a estabilização ou melhora clínica induzida pelo tratamento inicial ${ }^{12,13}$. As FRTs devem ser diferenciadas da progressão clínica sem qualquer resposta inicial ao tratamento. A visão geral é que uma FRT sinaliza que o efeito terapêutico passou enquanto a fase inflamatória da doença ainda está em andamento. Portanto, pacientes com SGB que apresentam FRTs podem se beneficiar de tratamento adicional, e repetir o curso total de IVIg ou plasmaférese nesses pacientes é uma prática comum, embora não haja evidências para embasar essa abordagem ${ }^{80}$.

\section{PDIC}

Em $\sim 5 \%$ dos pacientes com SGB, as recidivas clínicas repetidas sugerem um processo mais crônico da doença e o diagnóstico é alterado para polineuropatia desmielinizante inflamatória crônica (PDIC) de surgimento agudo ${ }^{12}$. A PDIC de surgimento agudo se apresenta tipicamente com três ou mais FRTs e/ou deterioração clínica após oito ou mais semanas do surgimento da doença ${ }^{12}$. 


\section{Etapa 9: previsão do resultado}

A maioria dos pacientes com SGB, mesmo aqueles que estavam tetraplégicos no nadir ou precisaram de ventilação mecânica por um longo período de tempo, apresenta ampla recuperação, principalmente no primeiro ano após o surgimento da doença ${ }^{11,99}$. Cerca de $80 \%$ dos pacientes com SGB recuperam a capacidade de caminhar sem auxílio após seis meses do surgimento da doença. ${ }^{11} \mathrm{~A}$ probabilidade de recuperar a capacidade de andar pode ser calculada em pacientes individuais usando a ferramenta prognóstica modified Erasmus GBS outcome score (Escala Erasmus de Prognóstico da SGB modificada) (mEGOS) ${ }^{100}$ (Tabela suplementar 3;

disponível em: https://www.ncbi.nlm.nih.gov/pmc/articles/PMC6821638/bi n/41582 2019250 MOESM1 ESM.pdf).

Apesar das perspectivas geralmente positivas para pacientes com SGB, a morte ocorre em 3\% a 10\% dos casos, mais comumente devido às complicações respiratórias e cardiovasculares que podem ocorrer tanto na fase aguda como na fase de recuperação ${ }^{7-9}$. Os fatores de risco para mortalidade incluem idade avançada e doença grave no surgimento7. Queixas residuais de longo prazo também são comuns e podem incluir dor neuropática, fraqueza e fadiga101-103. No entanto, a recuperação dessas queixas ainda pode ocorrer mais de cinco anos após o surgimento da doença ${ }^{103}$.

Episódios recorrentes de SGB são raros, afetando de $2 \%$ a $5 \%$ dos pacientes, mas essa porcentagem ainda é 
maior do que o risco de SGB ao longo da vida na população geral $(0,1 \%)^{14,15}$. Muitas vacinas possuem um aviso sobre a SGB, embora o histórico de SGB não seja uma contraindicação estrita à vacinação. Pode ser útil consultar um especialista no caso de pacientes que foram diagnosticados com SGB menos de um ano antes de uma vacinação planejada ou que tenham desenvolvido SGB pouco depois de receber a mesma vacina no passado. Nesses pacientes, os benefícios da vacinação para doenças específicas (por exemplo, gripe em idosos) devem ser ponderados contra o risco pequeno e possivelmente apenas teórico de um episódio recorrente da SGB ${ }^{14}$.

\section{Etapa 10: planejamento da reabilitação}

Pacientes com SGB podem apresentar uma série de problemas residuais de longo prazo, incluindo a recuperação incompleta da função motora e sensorial, bem como fadiga, dor e sofrimento psicológico ${ }^{103}$. Antes de o paciente receber alta, esses possíveis efeitos de longo prazo da SGB devem ser considerados e manejados ${ }^{104,105}$.

\section{Função física}

Providenciar um programa de reabilitação com um especialista em reabilitação, fisioterapeuta e terapeuta ocupacional é um passo fundamental para a recuperação. Os programas devem ter como objetivo a redução da incapacidade nos estágios iniciais da recuperação e, posteriormente, o restabelecimento da função motora e 
sensorial e da condição física aos níveis anteriores à doença ${ }^{106}$. Foi demonstrado que programas de exercícios para pacientes com SGB, que incluem exercícios de amplitude de movimento, bicicleta ergométrica e treinos de caminhadas e de fortalecimento, melhoram a condição física, a capacidade de caminhar e a independência nas atividades da vida diária ${ }^{106}$. No entanto, a intensidade do exercício deve ser atentamente monitorada, pois esforço excessivo pode causar fadiga ${ }^{106}$.

\section{Fadiga}

A fadiga, não relacionada às deficiências motoras residuais, é observada em $60 \%$ a $80 \%$ dos pacientes com SGB e é, frequentemente, uma das queixas mais incapacitantes ${ }^{107,108}$. Outras causas devem ser consideradas antes de concluir que a fadiga de um paciente é uma queixa residual da SGB. Assim como na recuperação da função física, demonstrou-se que um programa de exercícios gradativo e supervisionado é eficaz na redução na fadiga ${ }^{109}$.

\section{Dor}

É relatada dor intensa em pelo menos um terço dos pacientes com SGB um ano após o surgimento da doença e pode persistir por mais de dez anos ${ }^{14,26}$. A dor crônica na SGB é caracterizada por dor muscular na região lombar e nos membros, parestesia dolorosa, artralgia e dor radicular. Embora a patogênese dessa dor não seja totalmente compreendida, a dor muscular e a artralgia podem ser 
atribuíveis à imobilidade e a dor neuropática pode ser causada pela regeneração ou dano persistente de fibras nervosas pequenas ${ }^{26}$. As estratégias de manejo incluem encorajar a mobilização e a administração de medicamentos para dor neuropática ou nociceptiva ${ }^{104}$.

\section{Sofrimento psicológico}

A perda rápida da função física, muitas vezes em sujeitos anteriormente saudáveis, pode ser muito traumática

e causar ansiedade e/ou depressão. O reconhecimento e manejo precoces do sofrimento psicológico são importantes em pacientes com SGB, principalmente porque o status mental pode influenciar a recuperação física e vice-versa; o encaminhamento para um psicólogo ou psiquiatra pode ser benéfico para alguns pacientes ${ }^{110}$. $O$ fornecimento de informações exatas sobre a chance relativamente boa de recuperação e o baixo risco de recorrência ( $2 \%$ a $5 \%$ ) pode ajudar a diminuir o medo dos pacientes ${ }^{11,14}$. Conectar os pacientes com outros que tiveram SGB também pode ajudar a orientá-los através do processo de reabilitação. A GBS/CIDP Foundation International, a associação internacional para pacientes com SGB, e outras organizações nacionais podem auxiliar no estabelecimento de tais redes. 


\section{CONCLUSÕES}

A SGB pode ser uma doença difícil de diagnosticar e manejar, pois a apresentação clínica é heterogênea e o prognóstico varia bastante entre pacientes. O manejo da SGB pode ser especialmente desafiador durante os surtos desencadeados por doenças infecciosas, como visto mais recentemente durante a epidemia do vírus Zika. Na ausência de uma diretriz clínica internacional para a SGB, nós elaboramos esta diretriz consensual para o diagnóstico e manejo da SGB. Esta diretriz foi elaborada por uma equipe de neurologistas clínicos de todo o mundo e foi concebida para aplicação geral em todos as unidades clínicas, independentemente das competências especializadas ou da disponibilidade de recursos. O formato passo a passo foi usado para focar a atenção nos principais problemas da SGB e para tornar a diretriz fácil de usar na prática clínica.

Esta diretriz precisará ser atualizada com regularidade, pois o campo da pesquisa sobre a SGB evolui e os estudos em andamento têm como finalidade aprimorar o diagnóstico, o tratamento e a modelagem prognóstica. Por exemplo, o ultrassom dos nervos periféricos está surgindo com uma possível ferramenta diagnóstica e pode necessitar de comentários adicionais nas futuras versões desta diretriz. Em relação ao tratamento, a eficácia dos inibidores de complemento, das enzimas de clivagem de IgG e de um segundo tratamento com IVIg estão em investigação ${ }^{78,111,112}$. Sabe-se pouco sobre como medir e prever o resultado de longo prazo de pacientes com SGB, e são necessários 
estudos de validação de modelos prognósticos conhecidos (por exemplo, mEGOS e EGRIS) e pesquisa sobre novas medidas de resultados. Pretendemos buscar feedback sobre esta diretriz e fornecer atualizações com base nos resultados dos estudos em andamento e nas pesquisas futuras.

Para melhorar ainda mais o manejo global da SGB, visamos usar este relatório consensual como base para 0 desenvolvimento de recursos de informações, material de treinamento e cursos de ensino on-line. Esses recursos serão destinados a profissionais da saúde, incluindo neurologistas clínicos, assim como a pacientes com SGB e seus parentes.

\section{Pontos principais}

- A síndrome de Guillain-Barré (SGB) clássica é uma neuropatia sensitivo-motora ascendente de surgimento agudo, mas a doença pode se apresentar de maneira atípica ou como uma variante clínica.

- Os resultados anormais nos estudos eletrofisiológicos e uma combinação de nível proteico elevado e contagem celular normal no líquido cefalorraquidiano (LCR) são características clássicas da SGB, mas os pacientes com SGB podem apresentar resultados normais em ambos os testes, principalmente no início do curso da doença.

- A função respiratória deve ser monitorada em todos os pacientes, pois a insuficiência respiratória pode ocorrer sem sintomas de dispneia. 
- A imunoglobulina intravenosa e a plasmaférese são igualmente eficazes no tratamento da SGB; não se comprovou a eficácia de nenhum outro tratamento.

- A eficácia de repetir o tratamento em pacientes com resposta clínica insuficiente é incerta. No entanto, esta prática é comum em pacientes que apresentam deterioração após uma resposta inicial ao tratamento.

- A melhora clínica é geralmente maior no primeiro ano após o surgimento da doença e pode continuar por mais de 5 anos.

\section{Links relacionados}

GBS/CIDP

Foundation

International:

https://www.gbs-cidp.org/

Ferramenta de prognóstico do International GBS outcome study (IGOS):

https://gbstools.erasmusmc.nl/prognosis-tool

\section{AGRADECIMENTOS}

Gostaríamos de agradecer à Lisa Butler (diretora executiva, GBS/CIDP Foundation International) por sua contribuição na revisão do manuscrito. C.A.P., C.S., M.L.B.F., M.R.M. e S.E.L. são apoiados por um subsídio da União Europeia (Horizon 2020, ZikaPLAN Grant Agreement [Acordo de subsídio do ZikaPLAN] n.o 734584). H.J.W. é apoiado por um subsídio da União Europeia (Horizon 2020, ZikaPLAN Grant Agreement n. ${ }^{0}$ 734584) e pela fundação Wellcome Trust. B.C.J. é apoiado por um subsídio da União 
Europeia (Horizon 2020, ZikaPLAN Grant Agreement n.0 734584) e recebeu auxílio financeiro da Prinses Beatrix Spierfonds e da GBS/CIDP Foundation International. F.d.A.A.G. é apoiado por um subsídio do Conselho Nacional de Desenvolvimento Científico e Tecnológico (CNPq). D.R.C. faz parte do conselho de diretores da Peripheral Nerve Society. P.A.v.D. recebeu um subsídio da Prinses Beatrix Foundation para o ensaio randomizado controlado SID-GBS. S.K. é apoiado por um subsídio do Ministério da Educação, Cultura, Esportes, Ciência e Tecnologia do Japão (Subsídios para o apoio à pesquisa científica, 18H02745) e do Ministério da Saúde, Trabalho e Bem-Estar do Japão (Subsídio para pesquisa nas ciências da saúde e do trabalho). N.S. é apoiado por subsídios do Ministério Malaio da Educação (FP043-2018A) e da ALS Association. T.U. é apoiado por um subsídio da GBS/CIDP Foundation International. E.Y. é apoiado por um subsídio do National Health and Medical Research Council of Australia (Conselho Nacional de Saúde e Pesquisa Médica da Austrália) (Early Career Fellowship [Bolsa de início de carreira]).

\section{INFORMAÇÃO SUPLEMENTAR}

Disponível em:

https://www.ncbi.nlm.nih.gov/pmc/articles/PMC6821638/bi n/41582 2019250 MOESM1 ESM.pdf

(http://dx.doi.org/10.1038/s41582-019-0250-9) 


\section{REFERÊNCIAS}

1.Sejvar JJ, Baughman AL, Wise M, Morgan OW. Population incidence of Guillain-Barré syndrome: a systematic review and meta-analysis. Neuroepidemiology 2011;36:123-33.

http://dx.doi.org/10.1159/000324710

2.Asbury AK, Arnason BGW, Karp HR, McFarlin DE. Criteria for diagnosis of Guillain-Barré syndrome. Ann Neurol 1978;3:565-6. http://dx.doi.org/10.1002/ana.410030628

3.Asbury AK, Cornblath DR. Assessment of current diagnostic criteria for Guillain-Barré syndrome. Ann Neurol 1990;27(Suppl):S21-4. http://dx.doi.org/10.1002/ana.410270707

4.Sejvar JJ, Kohl KS, Gidudu J, Amato A, Bakshi N, Baxter R, et al. Guillain-Barré syndrome and Fisher syndrome: case definitions and guidelines for collection, analysis, and presentation of immunization safety data. Vaccine 2011;29:599-612.

http://dx.doi.org/10.1016/j.vaccine.2010.06.003

5. Hadden RD, Cornblath DR, Hughes RAC, Zielasek J, Hartung HP, Toyka KV, et al. Electrophysiological classification of Guillain-Barré syndrome: clinical associations and outcome. Ann Neurol 1998;44:780-8. http://dx.doi.org/10.1002/ana.410440512

6. Willison $\mathrm{HJ}$, Jacobs $\mathrm{BC}$, van Doorn PA. Guillain-Barré syndrome. Lancet 2016;388:717-27. http://dx.doi.org/10.1016/S0140$6736(16) 00339-1$

7.Van den Berg B, Bunschoten C, van Doorn PA, Jacobs BC. Mortality in Guillain-Barré syndrome. Neurology 2013;80:1650-4. http://dx.doi.org/10.1212/WNL.0b013e3182904fcc

8.Dominguez-Moreno $R$, Tolosa-Tort $P$, Patiño-Tamez A, QuinteroBauman A, Collado-Frías DK, Miranda-Rodríguez MG, et al. Mortalidad asociada al diagnostico de sindrome de Guillain-Barré en adultos ingresados en instituciones del sistema sanitario Mexicano. Rev Neurol 2014;58:4-10. https://doi.org/10.33588/rn.5801.2013370

9.Dourado ME, Felix RH, da Silva WK, Queiroz JW, Jeronimo SM. Clinical characteristics of Guillain-Barre syndrome in a tropical country: a Brazilian experience. Acta Neurol Scand 2012;125:47-53. https://doi.org/10.1111/j.1600-0404.2011.01503.x

10.Fokke C, van den Berg B, Drenthen J, Walgaard C, van Doorn PA, Jacobs BC. Diagnosis of Guillain-Barré syndrome and validation of Brighton criteria. Brain 2014;137:33-43.

http://dx.doi.org/10.1093/brain/awt285

11. Doets AY, Verboon C, van den Berg B, Harbo T, Cornblath $\mathrm{DR}$, Willison $\mathrm{HJ}$, et al. Regional variation of Guillain-Barré syndrome. Brain 2018;141:2866-77. http://dx.doi.org/10.1093/brain/awy232

12. Ruts L, Drenthen J, Jacobs BC, van Doorn PA. Dutch Guillain-Barré syndrome Study Group. Distinguishing acute-onset CIDP from fluctuating Guillain-Barré syndrome: a prospective study. Neurology 2010;74:1680-6. http://dx.doi.org/10.1212/WNL.0b013e3181e07d14 13. Kleyweg RP, van der Meche FG. Treatment related fluctuations in Guillain-Barré syndrome after high-dose immunoglobulins or plasma- 
exchange. J Neurol Neurosurg Psychiatry 1991;54:957-60. http://dx.doi.org/10.1136/jnnp.54.11.957

14. Kuitwaard K, Bos-Eyssen ME, Blomkwist-Markens PH, van Doorn

PA. Recurrences, vaccinations and long-term symptoms in GBS and CIDP. J Peripher Nerv Syst 2009;14:310-15.

http://dx.doi.org/10.1111/j.1529-8027.2009.00243.x

15.Principi N, Esposito S. Vaccine-preventable diseases, vaccines and Guillain-Barré syndrome. Vaccine 2019;37:5544-50. http://dx.doi.org/10.1016/j.vaccine.2018.05.119

16.Yuki N. Infectious origins of, and molecular mimicry in, GuillainBarre and Fisher syndromes. Lancet Infect Dis 2001;1:29-37. http://dx.doi.org/10.1016/S1473-3099(01)00019-6

17. Yoshikawa K, Kuwahara M, Morikawa M, Fukumoto Y, Yamana $M$, Yamagishi $Y$, et al. Varied antibody reactivities and clinical relevance in anti-GQ1b antibody-related diseases. Neurol Neuroimmunol Neuroinflamm 2018;5:e501.

https://doi.org/10.1212/NXI.0000000000000501

18.Jacobs BC, Rothbarth PH, van der Meché FGA, Herbrink $P$, Schmitz PIM, de Klerk MA, et al. The spectrum of antecedent infections in Guillain-Barre syndrome: a case-control study. Neurology 1998;51:1110-5. http://dx.doi.org/10.1212/wnl.51.4.1110

19. World Health Organization. Zika situation report 5 February 2016. World Health Organization, 2016. Disponivel em: https://www.who.int/emergencies/zika-virus/situation-report/5-

february-2016/en/

20.Cao-Lormeau VM, Blake A, Mons $S$, Lastère $S$, Roche $C$, Vanhomwegen J, et al. Guillain-Barre Syndrome outbreak associated with Zika virus infection in French Polynesia: a case-control study. Lancet 2016;387:1531-9. http://dx.doi.org/10.1016/S01406736(16)00562-6

21.Parra B, Lizarazo J, Jiménez-Arango JA, Zea-Vera AF, GonzálezManrique G, Vargas J, et al. Guillain-Barré syndrome associated with Zika virus infection in Colombia. N Engl J Med 2016;375:1513-23. http://dx.doi.org/10.1056/NEJMoa1605564

22. Wilder-Smith A, Preet R, Renhorn KE, Ximenes RA, Rodrigues LC, Solomon $\mathrm{T}$, et al. ZikaPLAN: Zika Preparedness Latin American Network. Glob Health Action 2017;10:1398485. http://dx.doi.org/10.1080/16549716.2017.1398485

23.Jacobs BC, van den Berg B, Verboon C, Chavada G, Cornblath $\mathrm{DR}$, Gorson $\mathrm{KC}$, et al. International Guillain-Barre Syndrome Outcome Study: protocol of a prospective observational cohort study on clinical and biological predictors of disease course and outcome in GuillainBarre syndrome. J Peripher Nerv Syst 2017;22:68-76. http://dx.doi.org/10.1111/jns.12209 
24.Ropper AH, Wijdickr EFM, Truax BT. Guillain-Barré Syndrome. FA Davis Company, 1991, Ch.12, p.155-60.

25.Van den Berg B, Walgaard C, Drenthen J, Fokke C, Jacobs CB, van Doorn PA. Guillain-Barré syndrome: pathogenesis, diagnosis, treatment and prognosis. Nat Rev Neurol 2014;10:469-82. http://dx.doi.org/10.1038/nrneurol.2014.121

26. Ruts L, Drenthen J, Jongen JLM, Hop WCJ, Visser GH, Jacobs BC, et al. Pain in Guillain-Barré syndrome: a long-term follow-up study. Neurology 2010;75:1439-47.

http://dx.doi.org/10.1212/WNL.0b013e3181f88345

27.Korinthenberg R, Schessl J, Kirschner J. Clinical presentation and course of childhood Guillain-Barré syndrome: a prospective multicentre study. Neuropediatrics 2007;38:10-7. http://dx.doi.org/10.1055/s2007-981686

28.Roodbol J, de Wit MCY, Walgaard C, de Hoog M, CatsmanBerrevoets $C E$, et al. Recognizing Guillain-Barré syndrome in preschool children. Neurology 2011;76:807-10.

http://dx.doi.org/10.1212/WNL.0b013e31820e7b62

29.Yuki N, Kokubun N, Kuwabara S, Sekiguchi Y, Ito M, Odaka M, et al. Guillain-Barré syndrome associated with normal or exaggerated tendon reflexes. J Neurol 2012;259:1181-90.

http://dx.doi.org/10.1007/s00415-011-6330-4

30.Ito M, Kuwabara S, Odaka M, Misawa S, Koga M, Hirata K, et al. Bickerstaff's brainstem encephalitis and Fisher syndrome form a continuous spectrum: clinical analysis of 581 cases. J Neurol 2008;255:674-82. http://dx.doi.org/10.1007/s00415-008-0775-0

31.Wakerley BR, Uncini A, Yuki N, the GBS Classification Group. Guillain-Barré and Miller Fisher syndromes-new diagnostic classification. Nat Rev Neurol 2014;10:537.

http://dx.doi.org/10.1038/nrneurol.2014.138

32.Sekiguchi Y, Mori M, Misawa S, Sawai S, Yuki N, Beppu M, et al. How often and when Fisher syndrome is overlapped by Guillain-Barré syndrome or Bickerstaff brainstem encephalitis? Eur J Neurol 2016;23:1058-63. http://dx.doi.org/10.1111/ene.12983

33. Uncini A, Yuki N. Sensory Guillain-Barré syndrome and related disorders: an attempt at systematization. Muscle Nerve 2012;45:46470. http://dx.doi.org/10.1002/mus.22298

34. Odaka M, Yuki N, Yamada M, Koga M, Takemi T, Hirata $K$, et al. Bickerstaff's brainstem encephalitis: clinical features of 62 cases and a subgroup associated with Guillain-Barré syndrome. Brain 2003;126:2279-90. http://dx.doi.org/10.1093/brain/awg233

35.Ito M, Matsuno K, Sakumoto Y, Hirata K, Yuki N. Ataxic GuillainBarré syndrome and acute sensory ataxic neuropathy form a continuous spectrum. J Neurol Neurosurg Psychiatry 2011;82:294-9. http://dx.doi.org/10.1136/jnnp.2010.222836

36.Graus F, Titulaer MJ, Balu R, Benseler S, Bien CG, Cellucci T, et al. A clinical approach to diagnosis of autoimmune encephalitis. Lancet Neurol 2016;15:391-404.

http://dx.doi.org/10.1016/S1474-4422(15)00401-9 
37.Van den Berg B, van der Eijk AA, Pas SD, Hunter JG, Madden RG, Tio-Gillen AP, Dalton HR, et al. Guillain-Barré syndrome associated with preceding hepatitis E virus infection. Neurology 2014;82:491-7. http://dx.doi.org/10.1212/WNL.0000000000000111

38.Vellozzi C, Iqbal S, Broder K. Guillain-Barré syndrome, influenza, and influenza vaccination: the epidemiologic evidence. Clin Infect Dis 2014;58:1149-55. https://dx.doi.org/10.1093/cid/ciu005

39.Thornton CA, Latif AS, Emmanuel JC. Guillain-Barré syndrome associated with human immunodeficiency virus infection in Zimbabwe. Neurology 1991;41:812-5. http://dx.doi.org/10.1212/wnl.41.6.812 40.Islam B, et al. Guillain-Barré syndrome following varicella-zoster virus infection. Eur J Clin Microbiol Infect Dis 2018;37:511-8. http://dx.doi.org/10.1007/s10096-018-3199-5

41.Carod-Artal FJ, Wichmann O, Farrar J, Gascon J. Neurological complications of dengue virus infection. Lancet Neurol 2013;12:90619. http://dx.doi.org/10.1016/S1474-4422(13)70150-9

42. Wielanek AC, Monredon JD, Amrani ME, Roger JC, Serveaux JP. Guillain-Barré syndrome complicating a Chikungunya virus infection. Neurology 2007;69:2105-7.

http://dx.doi.org/10.1212/01.wnl.0000277267.07220.88

43.Cornblath DR, McArthur JC, Kennedy PG, Witte AS, Griffin JW. Inflammatory demyelinating peripheral neuropathies associated with human T-cell lymphotropic virus type III infection. Ann Neurol 1987;21:32-40. http://dx.doi.org/10.1002/ana.410210107

44.Schonberger LB, Bregman DJ, Sullivan-Bolyai JZ, Keenlyside RA, Ziegler DW, Retailliau HF, et al. Guillain-Barré syndrome following vaccination in the National Influenza Immunization Program, United States, 1976-1977. Am J Epidemiol 1979;110:105-23.

http://dx.doi.org/10.1093/oxfordjournals.aje.a112795

45. Burwen DR, Ball R, Bryan WW, Gibbs NA, Kliman R, Braun MM, et al. Evaluation of Guillain-Barré syndrome among recipients of influenza vaccine in 2000 and 2001. Am J Prev Med 2010;39:296-304. https://doi.org/10.1016/j.amepre.2010.05.022

46.Kaplan JE, Katona P, Hurwitz ES, Schonberger LB. Guillain-Barré syndrome in the United States, 1979-1980 and 1980-1981: lack of an association with influenza vaccination. JAMA 1982;248:698-700. http://dx.doi.org/10.1001/jama.1982.03330060038030

47.Lasky T, Terracciano GJ, Magder L, Koski CL, Ballesteros M, Nash $\mathrm{D}$, et al. The Guillain-Barré syndrome and the 1992-1993 and 19931994 influenza vaccines. N Engl J Med 1998;339:1797-802. http://dx.doi.org/10.1056/NEJM199812173392501

48.Juurlink DN, Stukel TA, Kwong J, Kopp A, McGeer A, RE Upshur, et al. Guillain-Barré syndrome after influenza vaccination in adults: a population-based study. Arch Intern Med 2006;166:2217-21. http://dx.doi.org/10.1001/archinte.166.20.2217

49.Kao JC, Brickshawana A, Liewluck T. Neuromuscular Complications of Programmed Cell Death-1 (PD-1) Inhibitors. Curr Neurol Neurosci Rep 2018;18:63. http://dx.doi.org/10.1007/s11910-018-0878-7 
50. Hiew FL, Rajabally YA. Malignancy in Guillain-Barré syndrome: A twelve-year single-center study. J Neurol Sci 2017;375:275-8. https://doi.org/10.1016/j.jns.2017.02.024

51.Rudant J, Dupont A, Mikaeloff Y, Bolgert F, Coste J, Weill A. Surgery and risk of Guillain-Barré syndrome. French Nat Epidemiol Study 2018,91:e1220-7.

http://dx.doi.org/10.1212/wnl.0000000000006246

52. Ho TW, Mishu B, Li CY, Gao CY, Cornblath DR, Griffin JW, et al. Guillain-Barré syndrome in northern China. Relationship to Campylobacter jejuni infection and anti-glycolipid antibodies. Brain 1995;118(Pt 3):597-605. http://dx.doi.org/10.1093/brain/118.3.597

53.Kuijf ML, van Doorn PA, Tio-Gillen AP, Geleijns K, Ang CW, Hooijkaas $\mathrm{H}$, et al. Diagnostic value of anti-GM1 ganglioside serology and validation of the INCAT-ELISA. J Neurol Sci 2005;239:37-44. http://dx.doi.org/10.1016/j.jns.2005.07.009

54.Uchibori A, Gyohda A, Chiba A. Ca(2+)-dependent anti-GQ1b antibody in GQ1b-seronegative Fisher syndrome and related disorders. J Neuroimmunol 2016;298:172-7.

https://doi.org/10.1016/j.jneuroim.2016.07.021

55.Guillain G. [Radiculoneuritis syndrome with hyperalbuminosis of cerebrospinal fluid without cellular reaction. Notes on clinical features and graphs of tendon reflexes]. Bell Mem Soc Med Paris 1916;40:146270.

56.Wong AH, Umapathi T, Nishimoto $Y$, Wang $Y Z$, Chan YC, Yuki N. Cytoalbuminologic dissociation in Asian patients with Guillain-Barré and Miller Fisher syndromes. J Peripher Nerv Syst 2015;20:47-51. http://dx.doi.org/10.1111/jns.12104

57.Vucic S, Cairns KD, Black KR, Chong PS, Cros D. Neurophysiologic findings in early acute inflammatory demyelinating polyradiculoneuropathy. Clin Neurophysiol 2004;115:2329-35. http://dx.doi.org/10.1016/j.clinph.2004.05.009

58. Meulstee J, van der Meche F. Electrodiagnostic criteria for polyneuropathy and demyelination: application in 135 patients with Guillain-Barré syndrome. Dutch Guillain-Barré Study Group.J Neurol Neurosurg Psychiatry 1995;59:482-6.

http://dx.doi.org/10.1136/jnnp.59.5.482

59.Berciano J, Sedano MJ, Pelayo-Negro AL, García A, Orizaola $P$, Gallardo $E$, et al. Proximal nerve lesions in early Guillain-Barré syndrome: implications for pathogenesis and disease classification. J Neurol 2017;264:221-36. http://dx.doi.org/10.1007/s00415-0168204-2

60.Kuwabara S, Sekiguchi Y, Misawa S. Electrophysiology in Fisher syndrome. Clin Neurophysiol 2017;128:215-9.

http://dx.doi.org/10.1016/j.clinph.2016.11.009

61.Rajabally YA, Durand MC, Mitchell J, Orlikowski D, Nicolas G. Electrophysiological diagnosis of Guillain-Barré syndrome subtype: could a single study suffice? J Neurol Neurosurg Psychiatry 2015;86:115-9. http://dx.doi.org/10.1136/jnnp-2014-307815 
62.Uncini A, Kuwabara S. The electrodiagnosis of Guillain-Barré syndrome subtypes: Where do we stand? Clin Neurophysiol 2018;129:2586-93. http://dx.doi.org/10.1016/j.clinph.2018.09.025

63.Van den Bergh PYK, Piéret $F$, Woodard JL, Attarian S, Grapperon AM, Nicolas $G$, et al. Guillain-Barré syndrome subtype diagnosis: A prospective multicentric European study. Muscle Nerve 2018;58:238. http://dx.doi.org/10.1002/mus.26056

64.Uncini A, Kuwabara S. Electrodiagnostic criteria for Guillain-Barré syndrome: a critical revision and the need for an update. Clin Neurophysiol 2012;123:1487-95.

http://dx.doi.org/10.1016/j.clinph.2012.01.025

65.Gorson KC, Ropper AH, Muriello MA, Blair R. Prospective evaluation of MRI lumbosacral nerve root enhancement in acute Guillain-Barré syndrome. Neurology 1996;47:813-7.

http://dx.doi.org/10.1212/wnl.47.3.813

66.Yikilmaz A, Doganay S, Gumus H, Per H, Kumandas S, Coskun A. Magnetic resonance imaging of childhood Guillain-Barré syndrome. Childs Nerv Syst 2010;26:1103-8. http://dx.doi.org/10.1007/s00381010-1197-8

67.Elrick MJ, Gordon-Lipkin E, Crawford TO, Van Haren K, Messacar $\mathrm{K}$, Thornton $\mathrm{N}$, et al. Clinical subpopulations in a sample of North American children diagnosed with Acute Flaccid Myelitis, 2012-2016. JAMA Pediatr 2019;173:134-9.

http://dx.doi.org/10.1001/jamapediatrics.2018.4890

68. Hopkins SE, Elrick MJ, Messacar K. Acute Flaccid Myelitis - Keys to diagnosis, questions about treatment, and future directions. JAMA Pediatr 2018;173:117-8.

http://dx.doi.org/10.1001/jamapediatrics.2018.4896

69. Maloney JA, Mirsky DM, Messacar K, Dominguez SR, Schreiner $T$, Stence NV. MRI findings in children with acute flaccid paralysis and cranial nerve dysfunction occurring during the 2014 enterovirus D68 outbreak. AJNR Am J Neuroradiol 2015;36:245-50. http://dx.doi.org/10.3174/ajnr.A4188

70.Gallardo E, Sedano MJ, Orizaola P, Sánchez-Juan P, GonzálezSuárez A, García A, et al. Spinal nerve involvement in early GuillainBarré syndrome: a clinico-electrophysiological, ultrasonographic and pathological study. Clin Neurophysiol 2015;126:810-9. http://dx.doi.org/10.1016/j.clinph.2014.06.051

71.Razali SNO, Arumugam T, Yuki N, Rozalli FI, Goh KJ, Shahrizaila N. Serial peripheral nerve ultrasound in Guillain-Barré syndrome. Clin Neurophysiol 2016;127:1652-6.

http://dx.doi.org/10.1016/j.clinph.2015.06.030

72.Vereninging Spierziekten Nederland, Nederlandse Vereniging van Revalidatieartsen, [Dutch Association of Muscular Diseases \& Dutch Society of Rehabilitation Specialists]. Multidisciplinaire richtlijn Guillain-Barré syndroom [Multidisciplinary guideline Guillain-Barré syndrome]. Vol. 1 103-112, 120-122 (Libertas, Bunnik, 2011).

73. Mehta S. Neuromuscular disease causing acute respiratory failure. Respir Care 2006;51:1016-21, discussion 1021-3. 
74.Walgaard C, Lingsma HF, Ruts L, Drenthen J, van Koningsveld R, Garssen MJP, et al. Prediction of respiratory insufficiency in GuillainBarré syndrome. Ann Neurol 2010;67:781-7. http://dx.doi.org/10.1002/ana.21976

75.Walgaard C, Lingsma HF, van Doorn PA, van der Jagt M, Steyerberg EW, Jacobs BC. Tracheostomy or not: Prediction of prolonged mechanical ventilation in Guillain-Barré Syndrome. Neurocrit Care 2017;26:6-13. http://dx.doi.org/10.1007/s12028-016-0311-5

76. Hughes RA, Swan AV, van Doorn PA. Intravenous immunoglobulin for Guillain-Barré syndrome. Cochrane Database Syst Rev 2014;CD002063.

http://dx.doi.org/10.1002/14651858.CD002063.pub6

77.Chevret S, Hughes RA, Annane D. Plasma exchange for GuillainBarré syndrome. Cochrane Database Syst Rev 2017;2:CD001798. http://dx.doi.org/10.1002/14651858.CD001798.pub3

78. Korinthenberg R, Schessl J, Kirschner J, Monting JS. Intravenously administered immunoglobulin in the treatment of childhood GuillainBarré syndrome: a randomized trial. Pediatrics 2005;116:8-14. http://dx.doi.org/10.1542/peds.2004-1324

79.The French Cooperative Group on Plasma Exchange in GuillainBarré Syndrome. Appropriate number of plasma exchanges in GuillainBarré syndrome. Ann Neurol 1997;41:298-306. http://dx.doi.org/10.1002/ana.410410304

80.Verboon C, van Doorn PA, Jacobs BC. Treatment dilemmas in Guillain-Barré syndrome. J Neurol Neurosurg Psychiatry 2017;88:34652. http://dx. doi.org/10.1136/jnnp-2016-314862

81. Raphael JC, Chevret S, Hughes RA, Annane D. Plasma exchange for Guillain-Barré syndrome. Cochrane Database Syst Rev 2012;CD001798.

http://dx.doi.org/10.1002/14651858.CD001798.pub2

82. Hughes RA, Swan AV, Raphaël JC, Annane D, van Koningsveld $R$, van Doorn PA. Immunotherapy for Guillain-Barré syndrome: a systematic review. Brain 2007;130:2245-57.

http://dx.doi.org/10.1093/brain/awm004

83.Van Koningsveld R, Schmitz PIM, Meché FGA, Visser LH, Meulstee J, van Doorn PA, et al. Effect of methylprednisolone when added to standard treatment with intravenous immunoglobulin for Guillain-Barré syndrome: randomised trial. Lancet 2004;363:192-6. http://dx.doi.org/10.1016/s0140-6736(03)15324-x

84. Islam MB, Islam Z, Rahman S, Endtz HP, Vos MC, van der Jagt M, et al. Small volume plasma exchange for Guillain-Barré syndrome in resource poor settings: a safety and feasibility study. Pilot Feasibility Stud 2017;3:40. http://dx.doi.org/10.1186/s40814-017-0185-0

85.Overell JR, Hseih ST, Odaka M, Yuki N, Willison HJ. Treatment for Fisher syndrome, Bickerstaff's brainstem encephalitis and related disorders. Cochrane Database Syst Rev 2007.

http://dx.doi.org/10.1002/14651858.CD004761.pub2 
86.Verboon C, Doets AY, Galassi G, Davidson A, Waheed W, Péréon Y, et al. Current treatment practice of Guillain-Barré syndrome. Neurology 2019;93:e59-76.

http://dx.doi.org/10.1212/WNL.0000000000007719

87. Tomimatsu T, Sugihara M, Nagai T, Sunada Y, Kimura T, Shimoya K. Guillain-Barré syndrome after trivalent influenza vaccination during pregnancy. Eur J Obstet Gynecol Reprod Biol 2016;201:225-6. http://dx.doi.org/10.1016/j.ejogrb.2016.03.031

88.Pacheco LD, Saad AF, Hankins GD, Chiosi G, Saade G. Guillain-Barré Syndrome in pregnancy. Obstet Gynecol 2016;128:1105-0. http://dx.doi.org/10.1097/AOG.0000000000001716

89.Branch DW, Porter TF, Paidas MJ, Belfort MA, Gonik B. Obstetric uses of intravenous immunoglobulin: successes, failures, and promises. J Allergy Clin Immunol 2001;108:S133-8. http://dx.doi.org/10.1067/mai.2001.117821

90.El-Bayoumi MA, El-Refaey AM, Abdelkader AM, El-Assmy MMA, Alwakeel AA, El-Tahan HM. Comparison of intravenous immunoglobulin and plasma exchange in treatment of mechanically ventilated children with Guillain-Barré syndrome: a randomized study. Crit Care 2011;15:R164.http://dx.doi.org/10.1186/cc10305

91.Michon B, Moghrabi A, Winikoff R, Barrette S, Bernstein ML, Champagne J, et al. Complications of apheresis in children. Transfusion 2007; 47:1837-42.

http://dx.doi.org/10.1111/j.1537-

2995.2007.01405.x

92.Kannan Kanikannan MA, Durga P, Venigalla NK, Kandadai RM, Jabeen AS, Borgohain R. Simple bedside predictors of mechanical ventilation in patients with Guillain-Barre syndrome. J Critical Care 2014;29:219-23.

https://doi.org/10.1016/j.jcrc.2013.10.026

93.Lawn ND, Fletcher DD, Henderson RD, Wolter TD, Wijdicks EF. Anticipating mechanical ventilation in Guillain-Barré syndrome. Arch Neurol 2001;58:893-8. https://doi.org/10.1001/archneur.58.6.893

94. Hughes RAC, Newsom-Davis JM, Perkin GD, Pierce JM. Controlled trial of prednisolone in acute polyneuropathy. Lancet 1978;312:750-3. https://doi.org/10.1016/S0140-6736(78)92644-2

95.Dhar R, Stitt L, Hahn AF. The morbidity and outcome of patients with Guillain-Barré syndrome admitted to the intensive care unit. J Neurol Sci 2008;264:121-8.

http://dx.doi.org/10.1016/j.jns.2007.08.005

96. Oczko-Walker M, Manousakis G, Wang S, Malter JS, Waclawik AJ. Plasma exchange after initial intravenous immunoglobulin treatment in Guillain-Barré syndrome: critical reassessment of effectiveness and cost-efficiency. J Clin Neuromuscul Dis 2010;12:55-61. http://dx.doi.org/10.1097/CND.0b013e3181f3dbbf

97. Farcas P, Avnun L, Frisher S, Herishanu YO, Wirguin I. Efficacy of repeated intravenous immunoglobulin in severe unresponsive GuillainBarré syndrome. Lancet 1997;350:1747.

http://dx.doi.org/10.1016/s0140-6736(97)24050-x 
98. Walgaard C, Jacobs BC, Lingsma HF, Steyerberg EW, Cornblath DR, van Doorn PA, et al. Second IVIg course in Guillain-Barré syndrome patients with poor prognosis (SID-GBS trial): Protocol for a doubleblind randomized, placebo-controlled clinical trial. J Peripher Nerv Syst 2018;23:210-5. http://dx.doi.org/10.1111/jns.12286

99.Van den Berg B, Storm EF, Garssen MJP, Blomkwist-Markens PH, Jacobs BC. Clinical outcome of Guillain-Barré syndrome after prolonged mechanical ventilation. J Neurol Neurosurg Psychiatry 2018. http://dx.doi.org/10.1136/jnnp-2018-317968

100.Walgaard C, Lingsma HF, Ruts L, van Doorn PA, Steyerberg EW, Jacobs BC. Early recognition of poor prognosis in Guillain-Barré syndrome. Neurology 2011;76:968-75.

http://dx.doi.org/10.1212/WNL.0b013e3182104407

101. Soysal A, Aysal F, Caliskan B, Dogan Ak P, Mutluay B, Sakalli N, et al. Clinico-electrophysiological findings and prognosis of Guillain-Barré syndrome-10 years' experience. Acta Neurol Scand 2011;123:181-6. http://dx.doi.org/10.1111/j.1600-0404.2010.01366.x

102.Bersano A, Carpo M, Allaria S, Franciotta D, A Citterio, NobileOrazio $E$. Long term disability and social status change after GuillainBarré syndrome. J Neurol 2006;253:214-8.

http://dx.doi.org/10.1007/s00415-005-0958-x

103.Forsberg A, Press R, Holmqvist LW. Residual disability 10 years after falling ill in Guillain-Barré syndrome: a prospective follow-up study. J Neurol Sci 2012;317:74-9.

http://dx.doi.org/10.1016/j.jns.2012.02.026

104. Hughes RA, Wijdicks EFM, Benson E, Cornblath DR, Hahn $A F$, Meythaler JM, et al. Supportive care for patients with Guillain-Barré syndrome. Arch Neurol 2005;62:1194-8.

http://dx.doi.org/10.1001/archneur.62.8.1194

105.Davidson I, Wilson C, Walton T, Brissenden S. Physiotherapy and Guillain-Barré syndrome: results of a national survey. Physiotherapy 2009;95:157-63. http://dx.doi.org/10.1016/j. physio.2009.04.001

106. Simatos Arsenault N, Vincent PO, Yu BHS, Bastien R, Sweeney A. Influence of exercise on patients with Guillain-Barré syndrome: a systematic review. Physiother Can 2016;68:367-76. http://dx.doi.org/10.3138/ptc.2015-58

107. Garssen MP, Van Koningsveld R, Van Doorn PA. Residual fatigue is independent of antecedent events and disease severity in GuillainBarré syndrome. J Neurol 2006;253:1143-6. http://dx.doi.org/10.1007/s00415-006-0163-6

108. Merkies IS, Schmitz PI, van der Meché FG, Samijn JP, van Doorn PA; Inflammatory Neuropathy Cause and Treatment (INCAT) group. Fatigue in immune-mediated polyneuropathies. Neurology 1999;53:1648-54. http://dx.doi.org/10.1212/wnl.53.8.1648

109. Garssen MPJ, Bussmann JBJ, Schmitz PIM, Zandbergen A, Welter TG, Merkies ISJ, et al. Physical training and fatigue, fitness, and quality of life in Guillain-Barré syndrome and CIDP. Neurology 2004;63:23935. http://dx.doi.org/10.1212/01.wnl.0000148589.87107.9c 
110.Bernsen RA, de Jager AE, Kuijer W, van der Meche FG, Suurmeijer TP. Psychosocial dysfunction in the first year after Guillain-Barré syndrome. Muscle Nerve 2010;41:533-9.

http://dx.doi.org/10.1002/mus.21536

111.Wang Y, Shi Q, Lv H, Hu M, Wang W, Wang Q, et al. IgG-degrading enzyme of Streptococcus pyogenes (IdeS) prevents disease progression and facilitates improvement in a rabbit model of GuillainBarré syndrome. Exp Neurol 2017;291:134-40. http://dx.doi.org/10.1016/j.expneurol.2017.02.010

112. Misawa S, Kuwabara S, Sato Y, Yamaguchi N, Nagashima $\mathrm{K}$, Katayama K, et al. Safety and efficacy of eculizumab in GuillainBarré syndrome: a multicentre, double-blind, randomised phase 2 trial. Lancet Neurol 2018;17:519-29. http://dx.doi.org/10.1016/S14744422(18)30114-5

113. Wakerley BR, Yuki N. Mimics and chameleons in Guillain-Barré and Miller Fisher syndromes. Pract Neurol 2015;15:90-9. http://dx.doi.org/10.1136/practneurol-2014-000937

114. Wakerley BR, Kokubun N, Funakoshi K, Nagashima T, Hirata K, Yuki N. Clinical classification of 103 Japanese patients with GuillainBarre syndrome. J Neurol Sci 2016;69:43-7.

http://dx.doi.org/10.1016/j.jns.2016.08.002

115. Hiew FL, Ramlan R, Viswanathan S, Puvanarajah S. Guillain-Barré Syndrome, variants \& forms fruste: Reclassification with new criteria. Clin Neurol Neurosurg 2017;158:114-8.

http://dx.doi.org/10.1016/j.clineuro.2017.05.006

116. Blum S, Reddel S, Spies J, McCombe P. Clinical features of patients with Guillain-Barré syndrome at seven hospitals on the East Coast of Australia. J Peripher Nerv Syst 2013;18:316-20. http://dx.doi.org/10.1111/jns5.12045

117.Peric S, Milosevic V, Berisavac I, Stojiljkovic O, BeslacBumbasirevic L, Marjanovic I, et al. Clinical and epidemiological features of Guillain-Barré syndrome in the Western Balkans. J Peripher Nerv Syst 2014;19:317-21. http://dx.doi.org/10.1111/jns.12096 118.Zhang G, Li Q, Zhang R, Wei X, Wang J, Qin X. Subtypes and Prognosis of Guillain-Barré Syndrome in Southwest China. PLoS ONE 2015;10:e0133520. http://dx.doi.org/10.1371/journal.pone.0133520 119. Mitsui Y, Kusunoki S, Arimura K, Kaji R, Kanda T, Kuwabara S, et al. A multicentre prospective study of Guillain-Barré Syndrome in Japan: a focus on the incidence of subtypes. J Neurol Neurosurg Psychiatry 2015;86:110. http://dx.doi.org/10.1136/jnnp-2013306509

120.Ishaque T, Islam MB, Ara G, Endtz HP, Mohammad QD, Jacobs BC, et al. High mortality from Guillain-Barré syndrome in Bangladesh. J Peripher Nerv Syst 2017;22:121-

6. http://dx.doi.org/10.1111/jns.12215 